University of Rhode Island

DigitalCommons@URI

Open Access Dissertations

2011

\title{
"I'm Telling On You": A Natural History of Disclosure of Childhood Sexual Abuse
}

Trudy-Ann K. Gayle

University of Rhode Island

Follow this and additional works at: https://digitalcommons.uri.edu/oa_diss

\section{Recommended Citation}

Gayle, Trudy-Ann K., "'I'm Telling On You": A Natural History of Disclosure of Childhood Sexual Abuse" (2011). Open Access Dissertations. Paper 1066.

https://digitalcommons.uri.edu/oa_diss/1066

This Dissertation is brought to you for free and open access by DigitalCommons@URI. It has been accepted for inclusion in Open Access Dissertations by an authorized administrator of DigitalCommons@URI. For more information, please contact digitalcommons-group@uri.edu. 
I'M TELLING ON YOU": A NATURAL HISTORY OF DISCLOSURE OF CHILDHOOD SEXUAL ABUSE

BY

TRUDY-ANN K. GAYLE

A DISSERTATION SUBMITTED IN PARTIAL FULFILLMENT OF THE REQUIREMENTS FOR THE DEGREE OF

DOCTOR OF PHILOSOPHY

IN

PSYCHOLOGY 
Abstract

The body of research that exists on disclosure of childhood sexual trauma is rich.

However, the literature on disclosure has a noticeable shortcoming. For example, there is little or no research that explores the relationship between a victims' perceived response to disclosure and whether this response has any impact on subsequent help-seeking behavior. As a result of their experience of disclosure, do adult survivors of sexual abuse resort to secrecy or maladaptive coping behaviors aimed at controlling the stressful situation (e.g., use of drugs, alcohol, distraction, avoidance, engaging in sexual risktaking behaviors)? Or do survivors of CSA utilize constructive strategies aimed at reducing the stress of being sexually molested by expanding the resources for dealing with it (e.g., speaking with friends, family, clergy, therapist, etc.). Examining the disclosure process of women and how the disclosure experience impacts future help seeking is important to understanding how women cope and heal from their sexual abuse experience. It has been documented in the literature that in comparison to men that women are more likely to experience feelings of depression and distress and it would be of importance to discern whether these subjective psychological experiences affect disclosure and help seeking behavior. This study utilized a clinical sample of six female participants, who were asked to take a retrospective look at the disclosure process and the response that they received to their disclosure. The study aimed to qualitatively examine whether or not response to disclosure had an effect on future help seeking behaviors and subsequent disclosure. Findings from the study indicate that a positive response to disclosure may not be the only determinant of future help seeking behavior as was 
previously thought. This study highlights that feeling supported is significant. In fact, support may serve as a buffer against some of the deleterious outcomes commonly associated with sexual trauma history. It appears that having strong family support from a maternal figure, a sense of belonging in the family, and having the perpetrator punished in some way were important aspects of the disclosure experience. Future studies should explore the role of support in future help seeking as support may be a better predictor of future help seeking among sexual abuse survivors. 


\section{Acknowledgements}

First of all I would like to thank my major professor Patricia Morokoff for her excellent mentorship throughout my graduate school journey. She has and continues to provide me with a balance. She gave me plenty of space to work independently yet, provided support when I needed it. As I close this chapter of my life and open another, I want to extend all my love and gratitude to my parents Dawn and Clive and my sister Danielle. My family means everything to me. They are the anchor that kept me grounded during this very long, difficult, and emotionally draining process. I thank them for their emotional support, financial support, encouragement, patience, and most of all their unconditional and unwavering love. I could not have done it without them. This process has strengthened my faith and conviction that through the grace and mercy of God, all things are possible. 


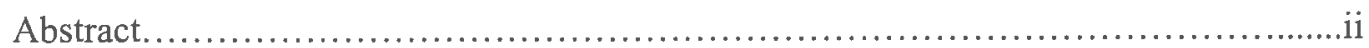

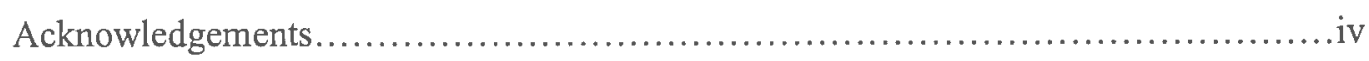

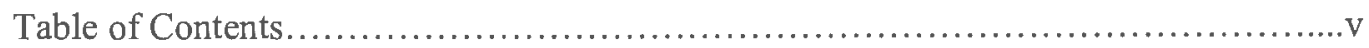

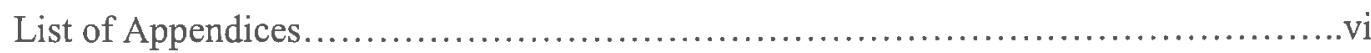

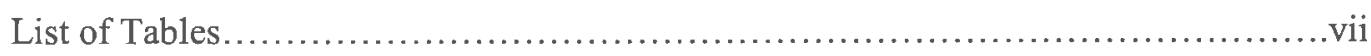

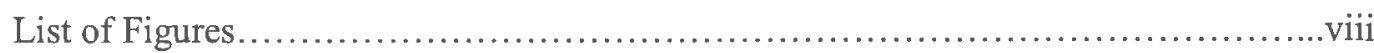

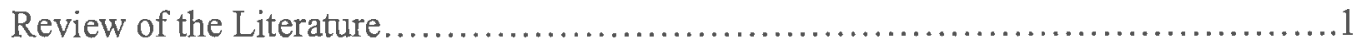

Cultural Assumptions in Disclosure.......................................... 10

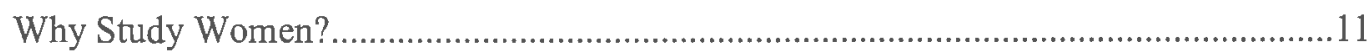

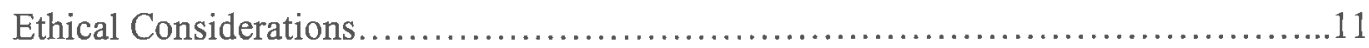

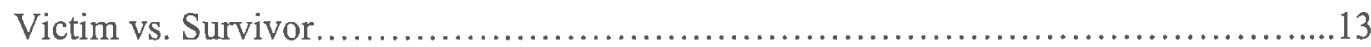

Purpose of the Current Study................................................. 14

Major Research Questions................................................... 15

Conducting Qualitative Research............................................ 16

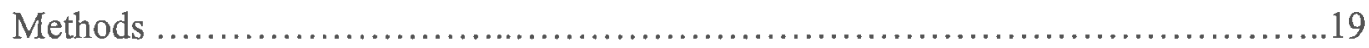

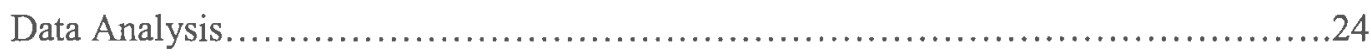

Quantitative Findings........................................................ 31

Qualitative Findings..........................................................

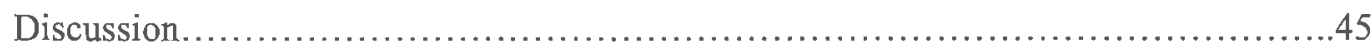

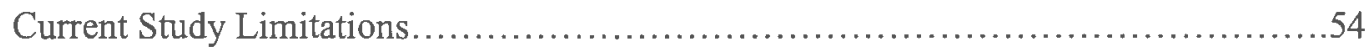

Recommendation for Clinicians.............................................. 55

Implications and Future Directions for Research.................................56

Bibliography....................................................... 94 
List of Appendices

Appendix I: Demographic Information and Qualitative Findings....................60 Appendix II: Diagnostic and Statistical Manual-IV (DSM-IV) Criteria for Posttraumatic

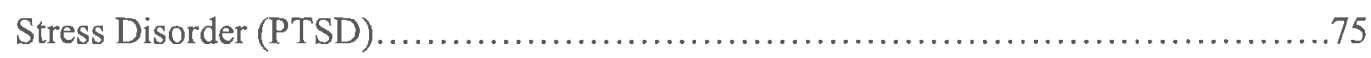

Appendix III: Structured Clinical Interview for Axis I Disorders (Posttraumatic Stress

Disorder Questionnaire) \& Interview Guide.................................. 78

Appendix IV: Demographic Questionnaire................................... 86

Appendix V: Informed Consent......................................... 89 


\section{List of Tables}

Table 1: Age of Sexual Abuse, Type of Sexual Abuse, Perpetrator, and Disclosure

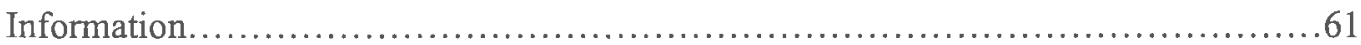

Table 2: Type of Disclosure and Perceived Disclosure Experience...................62

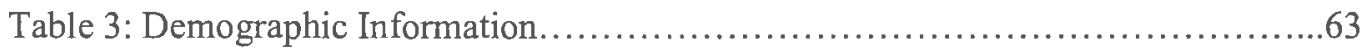

Table 4: Type of Psychiatric Treatment.......................................64

Table 5: Survivor Responses to Research Questions 1 and 2.......................65

Table 6: Survivor Responses to Research Question 3..............................66

Table 7: Survivor Responses to Research Question 4.............................67

Table 8: Survivor Responses to Research Question 5...........................68

Table 9: Survivor Responses to Research Question 6..........................69

Table 10: Survivor Responses to Research Question 7............................70

Table 11: Survivor Responses to Research Question 8............................. 71

Table 12: Psychological Sequalae for each Survivor................................. 72

Table 13: Percentage of Responses to SCID Items................................ 73 


\section{List of Figures}

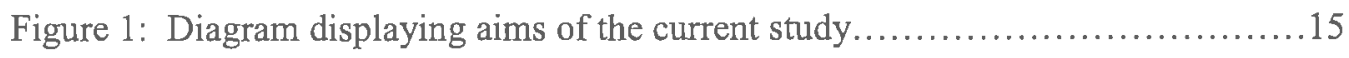


Review of the Literature

The body of research that exists on disclosure of childhood sexual trauma is rich. However, the literature on disclosure has a noticeable shortcoming. For example, there is little or no research that explores the relationship between a victims' perceived response to disclosure and whether this response has any impact on subsequent help-seeking behavior.

The research that exists on disclosure of CSA has highlighted various factors that inhibit or promote CSA disclosure (e.g., Hershkowitz et al., 2007; Alaggia, 2004; Somer \& Szwarcberg, 2001). For example, in the study conducted by Alaggia (2004), it was shown that gentle prompting promoted disclosure. When children are interviewed in a friendly context and are clearly and firmly encouraged to describe their experiences, they provide rich and detailed information about the abusive events. However, in studies conducted by Somer \& Szwarcberg (2001) and Alaggia (2004), some factors that inhibit CSA disclosure such as feelings of helplessnes, guilt and self blame, emotional attachment to the perpetrator, loyalty to the family, cultural norms reinforcing obedience, and mistrust of the judicial system were cited.

Other studies have drawn attention to the disclosure of sexual abuse and subsequent psychological adjustment (e.g., Nagel, Putnam \& Noll, 1997; Everill \& Waller, 1995). As a result of their experience of disclosure, do child victims of sexual abuse resort to secrecy or maladaptive coping behaviors aimed at controlling the stressful situation (e.g., use of drugs, alcohol, distraction, avoidance, engaging in sexual risktaking behaviors)? Or do victims of CSA utilize constructive strategies aimed at reducing the stress of being sexually molested by expanding the resources for dealing with it (e.g., 
speaking with friends, family, clergy, therapist, etc.). It has been noted that perceived response to disclosure is important in determining the extent of psychological disturbance following childhood sexual abuse (Everill \& Waller, 1995). Additionally, it is believed that perceived response to disclosure may be a key factor mitigating behaviors such as disclosing to others or attempting to solicit help from others.

\section{Childhood Sexual Abuse (CSA) and Psychological Sequelae}

Childhood sexual abuse (CSA) has been identified as a major public health problem. According to the American Academy of Child and Adolescent Psychiatry (AACAP) (2004), child sexual abuse is reported almost 90,000 times per year.

According to the U.S. Department of Justice national statistics, 1 out of 3 girls and 1 out of 5 boys will become victims of sexual abuse by the time they reach their $18^{\text {th }}$ birthday (www.justice.gov). However, the AACAP suggests that unreported abuse is far greater because many children are afraid to tell that they have been sexually violated. Therefore accurate statistics on the prevalence of CSA are difficult to attain. Underreporting accounts for some of the ambiguity surrounding prevalence; however, lack of a universal definition that constitutes abuse also contributes to the difficulty of generating accurate prevalence data. According to the American Psychological Association (APA), a central characteristic of any abuse is the dominant position that an adult forces or coerces a child into sexual activity. Their definition of child sexual abuse includes fondling a child's genitals, masturbation, oral-genital contact, digital penetration, and vaginal and anal intercourse. The definition of child sexual abuse may not solely be restricted to physical contact; such abuse could include noncontact abuse, such as exposure, voyeurism, and child pornography. Clearly a more inclusive definition will result in 
greater reports of prevalence. Abuse by peers is also considered to be a form of sexual exploitation (http://www.apa.org/releases/sexabuse/) and may be included in a definition. Sometimes, however, definitions of sexual abuse require an age differential between perpetrator and victim.

CSA has a wide number of psychological sequelae (Classen et al., 2005; BoneyMcCoy \& Finkelhor, 1998; Nagel et al., 1997). Among these are low self-esteem, anxiety, depression, anger and aggression, post- traumatic stress, dissociation, substance abuse, sexual difficulties, somatic preoccupation and disorder (particularly, pseudo seizures, pelvic pain, and gastrointestinal disturbances), self-injurious or self-destructive behavior, and most of the various symptoms and behaviors seen in those diagnosed with borderline personality disorder (Briere \& Elliot, 2003). Additionally, Matsakis (1991) found that children who have been sexually abused by a relative are more likely to suffer from depression and self-destructive behavior (such as substance abuse, sexual promiscuity and prostitution) than children who have been sexually assaulted by a stranger.

Posttraumatic Stress Disorder (PTSD)

Psychosocial risk factors for PTSD (The role of social context and gender). Psychosocial risk factors may be categorized into features of the traumatic event, preexisting attributes or experiences of the trauma victim, and post trauma circumstances. The majority of studies have quite understandably focused on identifying features of the traumatic event that make PTSD more or less likely. To this end, researchers have also examined the role that preexisting experiences play in PTSD. 
With regard to preexisting attributes, there is evidence that female gender, younger age at the time of trauma exposure, lower socioeconomic status (SES, lower education, lower intelligence, and minority racial/ethnic status emerge as risk factors for PTSD in trauma-exposed individuals (Brewin et al., 2000). Family instability and poor family functioning have been demonstrated to serve as a risk factor for PTSD in traumaexposed individuals.

With respect to post trauma characteristics, researchers have generally found two categories that may increase the likelihood of an adverse response to trauma (book). It has been found that lack of social support and exposure of additional life stressors.

Severity and PTSD. Brewin and colleagues' (2000) meta-analysis documented a modest association between event severity and PTSD. Traumatic events in which one is actively involved rather than merely a witness that involves subjective distress and especially dissociation at the time of the trauma and that are accompanied by lower magnitude stressors are most likely to lead to a dysfunctional response.

Disclosure of Sexual Abuse

How is disclosure defined? Paine and Hansen's (2002), classification of CSA into three categories that broadly define disclosure: (1) purposeful; (2) accidental; (3) prompted/elicited has been widely accepted in the literature. However, Alaggia (2004) suggest that the term "disclosure" is problematic because it is unclear whether it refers to the act of telling someone, or the more official act of reporting the abuse to an authority figure. The word "disclosure" is more commonly used in reference to a child's reporting of abuse (whether to an authority figure or not), while "telling" is more often used when 
adults share their abuse experience. The reporting of sexual abuse can be considered a developmental process ranging from "disclosure" in childhood to "telling" in adulthood.

Deciding to disclose. Sorenson and Snow (1991) challenged the notion that children disclose incidents of abuse readily and explicitly when they are approached for the first time about whether or not they are being sexually victimized. They found that most children, when confronted denied abuse but later disclosed and that about $20 \%$ of children participating in their study recanted, but the majority reaffirmed.

The decision to tell someone about abuse is fraught with danger for a child. A qualitative study conducted by Petronio, Flores, and Hecht (1997) using adolescent female participants noted that children often deliberate about whom they should disclose. Finding someone that is trustworthy is an important factor in disclosure. Adolescent girls who participated in the study noted that the choice of whom to tell is very significant. Their study found that children assess whether a confidant will use the knowledge of abuse in careless ways (e.g., for gossip). Based on the children's logic, they identified five factors that influenced who they disclosed to: credibility, support, advocacy, strength, and protectiveness. The participants from the study offered the following advice to other children, "the first person to tell, be sure it's somebody you can talk to. It doesn't have to be like a therapist or even a parent, be sure it is somebody you can talk to. So if you can't tell anybody else, then maybe you can depend on them to help you." The girls in the study repeatedly reported that adult responses mattered. This is consistent with studies that report children test the waters such as a more recent study by Alaggia (2004). She found some children attempted disclosure through behavioral manifestations (e.g. 
acting out, giving behavioral clues that something is amiss) but if the adults did not understand these attempts, the child abandoned the efforts.

Staller \& Nelson-Gardell ( 2005) posit that support and belief from significant others, particularly key family members, may be the difference between telling further or not, and recanting. They also note that the way an adult responds to partial disclosures, accidental disclosures, or indirect disclosures may be critical to whether a child will tell further. Thus, when these disclosures (which may be unintended as public disclosures) are made, not only is the initial reaction important, but so is the response of adults who subsequently learn of the information and confront the child.

Palesh et al., 2007 suggest that context is quite important in the disclosure experience of CSA. Their research suggests that when CSA occurs in the context of physical or emotional abuse and neglect, the distress experienced when telling one's story of sexual abuse is magnified. This indicates that the consequences of CSA are worse in family environments that are also physically abusive and neglectful. With regard to the long term effects of CSA, it appears that when a child is sexually abused at the same time there is emotional and physical abuse that the impact of disclosure is more likely to be severe.

Response to disclosure. In a qualitative review article of factors influencing children to self-disclose sexual abuse, twenty-one percent indicated that they disclosed in order to obtain support (Paine \& Hansen, 2002). However, it is unfortunate that many never receive the support they need following their traumatic experience. Results of two studies found nearly one child in ten who disclosed their sexual victimization reported their disclosure was received with disbelief (Berliner \& Conte, 1995). This increases their 
reluctance to disclose their abuse to anyone. This fear is not only one instilled by perpetrators to maintain the child's silence, it is one that is borne out of reality for too many children.

According to Hershkowitz, Lanes, \& Lamb (2007), researchers who have studied parental reactions to the disclosure of sexual abuse by their children note that parental, especially maternal, support following disclosure buffers against the harmful effects of sexual abuse and promotes the victims' emotion and psychological adjustment (Gries et al., 2000; Sinclair, 1999). However, according to Staller \& Nelson-Gardell (2005), the disclosure process is neither clear nor linear. They report that children delay, partially disclose, retract, affirmatively disclose, accidentally disclose, recant, and reaffirm. As a result, many responsible and caring adults can act unpredictably. They can discredit, denounce, challenge, threaten, and disbelieve.

Paine and Hansen (2002) noted a few barriers to supportive responses in mothers following discloure. They found that some family dynamics were associated with less maternal support. They found that mothers were less likely to be supportive when (1) the alleged perpetrator resided within the household compared to when the perpetrator lived elsewhere, (2) the reported abuser is closer to the family, rather than an unfamiliar perpetrator, (3) the victim reported more than one alleged perpetrator, and (4) disclosure occurred a year or more following cessation of the abuse. Delay in disclosure seemed to evoke more negative and unsupportive reactions in parents. Their study also revealed 4 family dynamic variables key to rejection after hearing about sexual abuse including (1) history of spousal abuse between the child's caretakers, (2) a chemically dependent caretaker, (3) a history of substantiated neglect of the child, or (4) physical abuse of the 
child by a caretaker. Other than family dynamic factors associated with disbelieving, they found that mothers were less likely to be supportive when (1) the alleged perpetrator resided within the household compared to when the perpetrator lived elsewhere, (2) the reported abuser is closer to the family, rather than an unfamiliar perpetrator, (3) the victim reported more than one alleged perpetrator, and (4) disclosure occurred a year or more following cessation of the abuse. Delay in disclosure seemed to evoke more negative and unsupportive reactions in parents. In the same study conducted by Hershkowitz, Lanes, \& Lamb (2007), results suggest that more of the parents participating in the study whose children delayed disclosure were unsupportive (81\%) than were parents whose children disclosed immediately (57\%). When children disclosed shortly after the incident, only $47 \%$ of parents were unsupportive compared to $85 \%$ who were unsupportive when the child's report was delayed.

It should be noted that a few studies looking at non-support in mothers of sexually abuse children revealed that inability to provide support may also be a reflection of maternal distress (Heflin, Deblinger, \& Fisher, 2000). Lack of support, disbelieving, and rejection reactions to disclosure among mothers is quite common, especially when mothers themselves had been victims of abuse (Alaggia \& Turton, 2005). An older study by Elliot and Briere (1994) found children whose mothers were non-supportive were significantly more likely to recant their initial report of abuse than children whose mothers were supportive ( $15.4 \%$ vs. $3.3 \%)$ possibly due to the negative reaction they had received.

Psychological distress associated with disclosure. Findings generated from studies regarding the psychological impact of disclosure versus non disclosure have 
varying results. A study conducted by Nagel et al. (1997) reported a strong relationship between disclosure of childhood sexual abuse and poor psychological functioning in adulthood, while others report that there is no relationship. According to Nagel and colleagues, psychological adjustment as influenced by the process of the disclosure of abuse may be a developmental one. They propose that the effects of disclosure may not be apparent at the time of the disclosure of the sexual abuse, but may manifest months or years later. They recommend that in order to capture the true impact of disclosure, it may be necessary to assess psychological functioning at several points in development.

An earlier study conducted by Elliott and Briere (1994) on sexual abuse disclosure and subsequent psychological adjustment 1-year following disclosure reported that children who disclosed abuse themselves had higher levels of psychological symptomatology such as anxiety, dissociation, and sexual concerns on the Trauma Symptom Checklist for Children (TSCC) than children who did not disclose their sexual trauma. This could very likely be attributed to the type of response that they received from the individual to whom they disclosed. Purposeful disclosure is associated with more negative effects than other disclosure types (Alaggia, 2004). Purposeful disclosure includes direct verbal attempts, intentional behavioral attempts (e.g., clinging, temper tantrums, angry outbursts, withdrawal, avoidance of home, or running away to alert adults that there is a problem), and indirect verbal attempts (e.g., leaving hints, asking parent(s) to stay home, asking not to go to the home or place where the abuse was taking place) (Alaggia, 2004). Another early study conducted by Everill \& Waller (1995) hypothesized that greater levels of psychopathology would be found in women who reported disclosing but receiving an adverse response. This hypothesis was supported. 
This study also noted that a perceived adverse response was associated with a lower level of internal control and a greater desire for control.

Palesh et al. (2007) suggest that self-capacities are related to ability to modulate and tolerate affect. Self-capacities are also important in forming and sustaining meaning relationships. Therefore, disclosing sexual abuse may likely stir up strong feelings toward oneself, and feelings about those who did not protect them. When the survivor's selfcapacities have been negatively impacted because of their abuse experience or life experiences, talking about their history of sexual abuse may elicit negative feelings and potentially greater distress and exacerbate already existing emotional problems such as depression and anxiety.

\section{Cultural Assumptions in Disclosure}

According to Alaggia (2004), certain cultural issues may act as deterrents to disclosure. Disclosure may be inhibited in cultures that hold negative attitudes and taboos about sexuality, and that place a high premium on preservation of the family (Paine \& Hansen, 2002; Alaggia, 2001). Additionally, structural factors such as discrimination, migration, and poverty have been identified as potential deterrents to disclosing CSA because children who have been marginalized because of the aforementioned factors may feel too disempowered to tell about abuse (Alaggia, 2004).

Although the research questions for this study do not specifically address the impact of race/ethnic identity on disclosure strategies and responses, it is believed that cultural factors do have bearing on the way in which a child approaches disclosure as well as the responses that are elicited. In fact, cultural factors may also play a role in coping strategies adopted by the survivor during and after the abuse. While culture is not 
directly addressed in the interview, it is believed that culture has a strong influence on the disclosure process and outcomes for the survivor. A question in the interview guide provided the participant the opportunity to discuss how their family or community values impacted their disclosure experience.

\section{Why Study Women?}

Examining the disclosure process of women and how the disclosure experience impacts future help seeking is important to understanding how women cope and heal from their sexual abuse experience. It has been documented in the literature that in comparison to men that women are more likely to experience feelings of depression and distress and it would be of importance to discern whether these subjective psychological experiences affect disclosure and help seeking behavior. Especially with women who have suffered from experiencing childhood sexual abuse and who are at greater risk of being sexually revictimized as an adult, their feelings of powerlessness and inability to cope could significantly impact their willingness to disclose as well as seek treatment.

\section{Ethical Considerations}

\section{Conducting Research with Vulnerable Populations}

According to Anderson \& Hatton (2000), accessing vulnerable populations for the purpose of research is complex. Not only can researchers have difficulty locating these participants, but also they must prevent their attrition from the study. Vulnerable persons face pressing socioeconomic needs that limit their time and energy they have available for participation in research. Furthermore, other barriers exist such as socioeconomic status, education, language, and /or ethnicity. These differences have consequences for 
how the researchers and participants view the importance and purpose of research. These differences can also impact communication.

Collecting data from vulnerable individuals especially using any form of interviewing frequently involves hearing detailed accounts of adverse life events (Anderson \& Hatton, 2000). In situations where research participants disclose unpleasant circumstances, the researcher not only has to take care of his or her well being, but must also ensure that the participants is not harmed in any way by sharing their experience. It may be necessary to suspend the research agenda to accommodate the needs of the participant. This is viable with semi-structured interviewing. Researchers must be sensitive to the issue of vulnerability and must ensure that the research being conducted will help the vulnerable population. In doing so, the researcher wants to minimize harm and promote good to all research participants, especially individuals from vulnerable groups. Therefore, it is a benefit to have a set of structured questions, but also have the ability to redirect participants when the need arises, or make informed decisions about whether to venture into a delicate subject area if a participant appears distressed. Conducting Research with Survivors of Childhood Sexual Abuse.

Working with survivors of childhood sexual trauma requires that a researcher has the ability to maintain a fine balance between objectivity and empathy. With a semistructured interview format, this balance can be achieved (Cowles, 1988). While the researcher has a set agenda of topics that he or she would like to cover, the flexibility still exists to provide participants with sensitivity that they are being understood and not being judged. 
Palesh et al. (2007) also report that severity of physical abuse, emotional abuse, and neglect in childhood and current self-capacities predicted distress in response to telling one's story of childhood sexual abuse. The study also revealed that self-capacities mediated the relationship between severity of childhood abuse and distress upon telling the story. This suggests that the more childhood abuse disrupts self-capacities, the more distress the adult survivor experiences when discussing the abuse.

One of the major ethical concerns in conducting research on sexual trauma is the traumatization of the researcher. In fact, the researcher may be particularly interested in this area of research because he or she has a past abuse history. In that event, listening to memories brought up by an abuse survivor may trigger many deep emotions for the researcher. Similarly, in situations where the researcher has not had a sexual abuse past, hearing horrifying stories of abuse may be difficult for even the most seasoned researcher. In the former situation, investigators must be concerned with retraumatization. In the latter scenario, the concern is vicarious traumatization.

Despite many training scenarios and attempts to prepare researchers for working with this population, sometimes the best training in the world cannot prepare a researcher for what he or she might encounter. As a result, researchers must not only be prepared prior to engaging with abuse survivors, but they must also be provided with supervision and an outlet to confidentially discuss some of the devastating stories that they hear.

\section{Victim vs. Survivor}

Throughout the study, participants are referred to as victim and survivor. It is important to discuss the rationale behind using both terms. The word victim implies that someone was subjected to participate in acts that they did not wish to have a part in. As a 
result, they became a victim of an unfortunate circumstance. The word victim does not imply that someone is weak or not resilient. It also does not imply that the individual who experienced the unfortunate situation should always be considered a victim. In the text, the word survivor is used to describe participants as they share their experience of being victimized. Usage of the word survivor in identifying participants stems from an empowerment based perspective. Referring to the female participants in the study as survivors implies that they have in some way risen beyond an unfortunate circumstance to share their experience. It suggests that they are no longer a victims of their circumstance and that they have the strength to heal and move forward from their past trauma (s),

\section{Purpose of the Current Study}

Why Study Disclosure Experience?

The previously discussed literature captures the problem of childhood sexual abuse and its numerous deleterious outcomes. This study utilized a clinical sample of female participants, who were asked to take a retrospective look at the disclosure process and the response that they received to their disclosure. The study aimed to qualitatively examine whether or not response to disclosure had an effect on future help seeking behaviors and subsequent disclosure.

Participants were asked to "reflect back" on their childhood disclosure experience. Asking participants to reflect on a traumatic time in their life or a traumatic experience such as being sexually abused can be difficult as well as evoke strong emotions. For participants who appeared to be experiencing difficulty in discussing their experience, resources for counseling were offered. This study did not ask participants to 
recall and or divulge explicit details of their sexual abuse experience, although some participants divulged specific details of their experience. The study had three main aims (see figure 1 below): (1) to explore survivors' self-perceived response after disclosure of sexual abuse, (2) to explore survivors' reaction (within 6 months to a year of following disclosure and thereafter), and (3) to explore whether or not survivors' self-perceived response had implications for help seeking/subsequent disclosure at the time of the abuse and thereafter. It was hypothesized that if disclosure experiences are met with positive regard, warmth, and openness as opposed to cynicism and disbelief, then victims would be less likely to succumb to the negative outcomes associated with being sexual victimized.

${ }^{(1)}$ CSA Disclosure $\rightarrow{ }^{(2)}$ Positive Response to Disclosure $\rightarrow{ }^{(3)}$ Increased Help-Seeking/Disclosure

Figure 1. Diagram displaying aims that were examined in the study.

This study is exploratory in nature and the results were interpreted cautiously and should not be generalized to all sexual abuse survivors.

\section{Major Research Questions}

Based on the previously mentioned research studies, boundaries transcended when a child is sexually molested not only impacts physical being, but also emotional wellness. From a developmental vantage point, CSA has deleterious implications throughout the lifespan. Through a semi-structured interview format, the following research questions were addressed (see full interview guide in Appendix II).

1. How do survivors of CSA describe their experience of disclosure?

2. Who did they disclose to and reasons for selecting this person?

3. What did survivors hope would happen as a result of the disclosure?

4. What barriers in disclosing did survivors perceive? 
5. How do survivors of CSA perceive their disclosure experience (e.g., positively or negatively, supportive, unsupportive)?

6. How did survivors react (e.g., behaviors) following the response to disclosure?

7. Did the survivors' perceived response following disclosure impact future help seeking and subsequent disclosure?

8. What suggestions would a survivor of CSA give to clinicians, teachers, parents regarding disclosure of CSA?

\section{Conducting Qualitative Research}

Why Use Qualitative Methodology?

When negotiating the complex dynamics of recovery work with adult survivors of CSA, many complex issues may arise. But, how does a clinician working with a survivor of abuse decide which direction to turn in order to provide crucial help necessary for a survivor's recovery? Clinical and empirical road signs are not always clear in providing direction for clinicians as the field of knowledge is still evolving (Enns et al., 1998). The reality of recovery work with sexual abuse victims is that it is not based on isolated variables and incidents. In fact, clinicians are faced with multilayered sequelae simultaneously presented by some survivors.

Many studies examining the impact of intervening variables have used quantitative, correlational designs. However, conclusions on the effects of CSA cannot be made simply on the basis of correlational data between current symptomatology and childhood experiences (Runtz \& Schallow, 1997). Sexual abuse occurs within the broader context of the individual's life, and what may appear to be the effects of CSA in an individual's life may in fact be due to other more recent experiences (Briere, 1997). 
My view concurs with that of Roth et al. (1997), who proposed that qualitative investigations, which allow for as clear a representation of the survivor's voice as possible, will be most likely to lead to an understanding of the traumatic dynamic, which influences behavior and which can become the target of therapeutic change.

It is often the belief that quantitative methods can stand on their own, but that qualitative approaches are not capable of the same. However, in an area that has not been firmly developed and researched, gathering qualitative data can be seen as the optimal method of gaining knowledge of topics that did not previously exist. Qualitative research should not be regarded as simply a cosmetic addition to a larger quantitative study. In many regards, the findings derived from qualitative inquiries can stand alone. In fact, they often stand as the foundation or cornerstone of research areas that are non-existent or underdeveloped.

An advantage of quantitative methods is that they provide generalizability. However the advantage of using qualitative methodologies is that the expectation of generalizability does not have to be met. Qualitative methods can be viewed as laying the groundwork for a topic under study, which may ultimately evolve into more expansive research endeavors with more hypotheses.

A strength of qualitative methods is that they embrace the idea that multiple truths exist. In studying, many realities exist for survivors of childhood sexual trauma. While the shared reality that they have endured a painful event exists, the intensity and severity of the abuse varies from survivor to survivor. Additionally, the type of abuse and the relationship of the perpetrator differ in each situation. 
The exploratory nature of this study warranted conducting semi-structured interviews. This approach helped to generate new insights on my area of interest through the sharing of experiences and the meaning(s) respondents make of their experiences. Exploratory studies can be conducted with quantitative approaches however; quantitative methods require that the researcher has some hypotheses about the area under study. In contrast, conducting exploratory studies using interviews does not require a researcher to generate hypotheses a priori. 
Methods

\section{Participants}

Six female participants for the study were recruited from a community mental health center in Southeastern Connecticut. The women were eligible if (1) they were older than age 18 and (2) had a history of CSA (e.g., touching, fondling, exhibitionism, penetration) that was disclosed prior to participation in this research study.

Participants were recruited from a community mental health center in Southeastern, Connecticut. They were asked to provide demographic information, such as current age, type of habituation (e.g., private residence without support, private residence with supports, shelter, 24-hour residential program), educational status, and employment status (e.g., unemployed, employed full-time, employed part-time). Participants were also asked to provide information about their current source of income.

All participants disclosed a history of touching, fondling, exhibitionism, or penetration. Participants were selected for the study by their ongoing therapist or case manager for having disclosed a history of sexual abuse that included touching, fondling, exhibitionism, or penetration (See Table 1).

Procedure and Data Collection

Once approval was received from the Institutional Review Board (IRB) of the University of Rhode Island, I began recruitment of women who had disclosed their childhood sexual abuse experience from a community mental health center in Southeastern Connecticut. I elicited the assistance of the Chief Executive Officer (CEO) and the Director of Quality Care to generate a list of potential participants for the study. They were provided with a brief description of the study and the IRB approval document. 
The Director of Quality Care communicated recruitment requirements with master's level social workers at the clinic during their weekly clinical meeting. Clinicians were asked to discuss the study with their ongoing female clients (older than 18 years old) who had disclosed a history of childhood sexual abuse to find out if they would be interested in participating. After approximately one week, I was provided with a list of six participants who verbally stated to their individual therapist or case manager that they would be interested in participating in the study. I was also provided with the phone numbers of the six women so that I could contact each one individually in order to briefly discuss the study and allow them to ask questions. The six participants that expressed interest in the study were the only six participants that could be recruited.

Each woman was contacted individually. All six women verbally consented to participating in the study over the phone. Women were scheduled to conduct the face-toface interviews based on their availability. On the evening prior to the interview, each woman was contacted to remind her of the appointment.

On the day of the study, a signed informed consent was obtained from each participant, describing the purpose of the study, as well as the risk and benefits associated with participation. Because this study involved the use of audiotape, participants were asked to sign an additional consent form that describes the procedures of maintaining confidentiality when using audiotapes and transcriptions (See Appendix IV for both consent forms). Participants received a copy of both consent forms.

Prior to conducting the interview, participants were asked to complete a selfreport demographic questionnaire. They were then asked questions from the PTSD module of the SCID. This took approximately 15 minutes to complete. 
The face-to-face interviews took place over the course of 2 days. On day one, one interview was conducted. On day two, 5 interviews were conducted between 8 am and 4 pm. All interviews were conducted at the community mental health center in a private location. Interviews lasted between 15 and 60 minutes. At the conclusion of the interview, study participants were given $\$ 25$ gift cards to a pharmacy of their choice as compensation for their participation.

Participants were not asked to discuss specific details of their sexual abuse experience. During the course of the interview, many women disclosed details such as who the perpetrator was, how long the abuse took place, and the age in which the abuse occurred. Participants were asked to describe the process leading up to their decision to disclose that they were sexually molested. They were also asked to describe their experience of disclosing and whether or not they perceived the response that they received as supportive or unsupportive. Participants were additionally asked to discuss potential barriers to disclosure that they perceived. The interview guide developed for this study was used in an effort to establish a general focus for the interview however, participants were allowed to share as little or as much as they felt comfortable sharing. Measures

Structured Clinical Interview for Axis I Disorders (SCID). First, participants were asked questions related to posttraumatic stress disorder (PTSD) symptomatology from the posttraumatic stress disorders module of the Structured Clinical Interview for Axis I Disorders (SCID) (Version 2003) (See Diagnostic and Statistical Manual criteria in Appendix I). Administering this module of the SCID (See appendix II) provided some descriptive information about whether the participant is experiencing any posttraumatic 
stress disorder (PTSD) related symptoms as a result of their sexual abuse experience(s). Then, participants were asked to complete a brief self-report survey packet including demographic information which took approximately 5 minutes to complete. Participants were asked to complete the PTSD module and the self report survey first, to allow them to feel more comfortable with the research process as well as being in the room with someone unfamiliar. By allowing participants to begin the research process with "yes" and "no" responses, it may have allowed participants to "warm up" to the fact that they may be answering questions of a similar nature or questions related to their sexual abuse experience during the interview portion of the study. Respondents were asked to indicate if they have received psychological treatment following the abuse, including pharmacotherapy, individual therapy, support groups, family therapy, inpatient mental health treatment, outpatient mental health treatment, or substance abuse treatment.

Semi-Structured Interview. Second, the semi-structured interview (See Appendix II) served as the qualitative portion of this study was administered. The purpose of the semi-structured portion of the study was to obtain information regarding the process of disclosure of their sexual abuse.

The format of a semi-structured interview is that the researcher has prepared a set of questions on specific topics that are organized around a particular area of interest. Unlike the unstructured interview, the researcher has a more clear-cut agenda and must gather certain data. The format still allows for flexibility, allowing new questions to be brought up during the interview.

Burnard (2005) defines the semi-structured interview as one in which either a) the interviewer refers to a sheet containing key areas to be covered in the interview or b) uses 
a set of questions but is prepared to insert other questions into the interview in order to capture elaborations. Dearnley (2005) further explains that the semi-structured interview allows all participants to be asked the same questions within a flexible framework. All participants are asked questions from the same set of questions, but there is no defined ordering of the questions. Participants were encouraged to talk about their experiences through open-ended questions, and the ordering of further questions is ultimately determined by their responses.

The open nature of the semi-structured interview was aimed at encouraging depth and vitality and to let new concepts emerge. Details can be obtained by asking for examples. The trustworthiness of the study was increased through data that is rich in description. This method is advantageous in that the researcher gets the data that he or she wants while using a structure or format. There is a subtle equilibrium being maintained through asking direct questions, follow up queries, and redirection. Organization and directedness can work in favor of the researcher and respondent who both may be pressed for time. Time is something to be considered for both researcher and participants. Thought should be given during the preparation stage of a study to exactly what you are asking of the participants. While they may not mind one or even two hourlong sessions, more than this may be an imposition. 


\section{Data Analysis}

\section{Quantitative}

Quantitative analyses for the demographic data collected in this study were analyzed using SPSS 18. Frequency and descriptive analyses were conducted.

\section{Qualitative}

The qualitative data gathered from this study was transcribed verbatim from the audio-taped interviews. Following transcription, data was cleaned to eliminate repetition (e.g., "and then, and then I went"), and unrelated sounds (e.g., "um", "uh", "like", "you know"). Data was edited to eliminate all possible identifiers. Pseudonyms were given to participants to ensure confidentiality.

When using the interview guide, I was careful to utilize the material that the participant had shared in order to ask my follow-up questions. I was additionally careful to avoid imposing my own interests on the experiences of the participants. As a researcher, I found the experiences of the participants intriguing and I was tempted on several occasions to follow-up on certain things that they shared (i.e. interpersonal relationships and re-victimization. However, I utilized the interview guide as a tool to maintain focus. Throughout the interview, I utilized interviewing techniques such as talking less and listening more, using follow-up questions, and avoiding leading or closed-ended questions. At the conclusion of the interview, each participant was asked the same three questions (1) If anything, what would you have changed about the way you disclosed? (2) Is there wish you had done differently? And (2) If you had the opportunity to speak to clinicians, teachers, parents regarding disclosure of CSA what would you want them to know? (See Appendix III). 
Rigor and Trustworthiness in this Study

Triangulation. Triangulation is another method of achieving rigor in data analysis. As the study unfolded and particular pieces of information came to light, steps were taken to validate each against at least one other source (for example, a second interview) and/or a second method (Lincoln \& Guba, 1985, p. 283). Triangulation in qualitative research is emphasized in order to curtail claims that the data found is invalid. In essence, if a statement was made by one informant and was supported by an informant in another interview, then the statement was deemed as valid. No single claim was given serious consideration unless it could be triangulated (Lincoln \& Guba, 1985).

Audit Trail. Achieving trustworthiness or rigor through maintaining an audit trail is regarded as the single most important trustworthiness technique available. Particularly when dealing with the consistency of data, a study is auditable when another researcher can clearly follow the decision trail used by the investigator (Koch, 2006). Maintaining an audit trail establishes confirmability. A researcher evaluating a study can ascertain whether the findings are grounded in the data. This can be determined rather easily if appropriate audit trail connections have been established. Audit trails are also another method of drawing conclusions about whether inferences drawn from the data are logical. Furthermore, if the study were to be replicated, another researcher could arrive at the same or comparable findings. Based on the information offered in a well maintained audit trail, persons evaluating the validity of a research study can make an independent assessment. 
Reflexivity. Also known as researcher reflexivity, or just reflexivity, this process generally refers to efforts by the researcher to incorporate or share reflections on the research process with the readers. It is also an attempt by the researcher to demonstrate their accountability through sharing a detailed presentation of the way in which the results were obtained (Henwood, 2008).

Henwood (2008) posits that the detailed methods and measurement sections incorporated in quantitative studies are not the norm in qualitative studies. Instead, researchers who conduct qualitative studies include methods sections which provide insight into the dynamics of the research process, the values and assumptions framing the research, and the social embeddedness of the research process for their impact on knowledge generation.

This can be seen as a strong suite of qualitative research because meaning is not only made for the participants; however, readers can hopefully grasp the meaning of a substantive societal issue from the stories of the participants. It is also the hope that the reader can gain understanding of a substantive issue through the way in which the research is presented and the way in which the narratives are displayed.

Henwood (2008) suggests that reflexivity in psychological studies can be achieved through approaching research from an emic standpoint. Adopting an emic research strategy seeks to grasp different ways of seeing the world to one's own.

Qualitative research encompasses objectivity, replication, reliability, validity, standardization, and rule (Davies \& Dodd, 2002). Based on this definition, there are some quantitative elements but, these elements that are typically characteristic of quantitative research can be applied to qualitative methods as well. Conceptually, rigor is the 
authoritative evaluation of good research which all research studies are subject to scrutiny. To establish trustworthiness or rigor in qualitative inquiry, Guba \& Lincoln (1989) appear to the criteria of credibility, transferability, and dependability. They assert that a study is credible when it presents faithful descriptions and when co-researchers or readers confronted with the findings can recognize the study as trustworthy.

Rose and Webb (1998) also cited these elements as essential to attaining rigor in data analysis: (1) being present during the interview(s), (2) Audio-taping the interview(s) and listening to the tape, (3) Transcribing the data, (4) Reading the transcription, and (5) Repeating steps 1 and 2 to ensure familiarity. Engaging in these aforementioned steps affords a safeguard for the researcher in the event that he or she is questioned about the steps taken to attain the data. A researcher can make reference to actually being present during the time of the interview(s) as well as having audio-taped verification that the interview(s) exist and were conducted in a manner that preserves structure and objectivity. Rose and Webb pinpoint that having familiarity with the data will lead to thinking about it more critically and intuitively. It also provides for a more analytical interpretation and thorough understanding of the findings.

Trustworthiness and reliability were achieved in several ways for this study for this study. I personally conducted each interview. Through being present during each interview, I became familiar with each participant's responses. I also made special effort to recall the stories and experiences that they shared with me. In addition to being present for the interviews, I also audio taped each interview. Following the interviews, I listened to the audio tape recordings to further acquaint myself with the data that were provided. I 
personally transcribed each interview and then read through each transcription to further ensure that I was gaining familiarity with the data.

Reflective notes. If face-to-face interviews are the mode of data gathering, maintaining field journals is important. According to Lincoln \& Guba (1985, p. 281), maintaining field will accumulate a great deal of information for subsequent analysis. They recommend that the researcher also keep three other forms of notes in a journal format. These include (1) a log of day-to-day activities, (2) a personal log or diary which will reveal different states of mind in relation to what is occurring during the interview process, and (3) a record of hypotheses and questions that will be useful to follow up or discuss once the interviewing phase has concluded.

For this study, reflective notes were used to keep me immersed in the data. I wrote brief notes following each interview to reflect and process the interview. I noted my thoughts and feelings about each interview as some of the information that the participants shared with me was sometimes overwhelming and difficult to hear. Keeping reflective notes also allowed the opportunity for more in-depth discussions about the interview process during peer review and supervision. I did not have a supervisor available during the days that I conducted the interviews, so keeping notes was a method of documenting what I was experiencing so that I could discuss it with my supervisor at a later time. This truly provided to be helpful not only for myself, but also for my supervisor who assisted me in generating themes that emerging.

One commonality that I realized among most participants is that they were very open to sharing their experiences. Discussing sexual abuse experience can be difficult, but presumably even more difficult to discuss with someone unfamiliar however, all six 
of the female survivors in this study appeared relatively comfortable sharing their sexual abuse experience within only a few minutes of meeting the interviewer. It is possible that the women in this study were more forthcoming about sharing their experience because all of them had previous therapy experience. Having discussed their experience in therapy may have increased comfort level. It is also plausible that my discussion with them over the phone helped them to mentally prepare for coming in a sharing their experience with me.

A few women who participated in the study discussed feeling that their experience was liberating because they hoped that their participation might help other women. This may have helped them to feel more comfortable sharing their experience if they felt that sharing would be valuable in some way. Advocacy has been shown to be a very powerful tool in healing for many survivors of sexual abuse.

It is also possible that the survivors felt comfortable discussing their disclosure experience because they were not asked to discuss specific details about their experience. Survivors were not aware that the interviewer is a psychology intern who has experience with counseling women with childhood sexual abuse experience. Survivors were only informed that they were being recruited for a study to discuss their disclosure experience of childhood sexual abuse.

Previous literature on disclosure of sexual abuse found that when reports of the abuse were received in a friendly context and are clearly and firmly encouraged to describe their experiences, that sexual abuse survivors would provide rich and detailed information about the abusive events. It is assumed that the survivors in this study provided rich information because they were firmly asked to describe their sexual abuse 
experience. All six survivors in the study had previously disclosed their sexual abuse experience which may have potentially contributed to their openess to disclosure during the study.

\section{Content Analysis}

Content analysis was used to analyze the data. Content analysis is defined as a systematic and dynamic approach for analyzing verbal data (Graneheim \& Lundman, 2004; Krippendorff, 1980, 2004). Data is broken down into smaller units, coded and then grouped together under shared concepts (Polit \& Beck, 2008). Graneheim and Lundman (2004) have described two types of content analysis that can be used when analyzing text. Manifest content analysis refers to what the text says and latent content refers to what the text is talking about and takes the context into account. Latent content analysis is more interpretive.

The analytic process began with the verbatim transcription of the audio-taped interviews. All possible identifiers were removed and pseudonyms were used to maintain the participants' confidentiality. Next, each transcript was read in its entirety several times to obtain a sense of the whole interview. Following readings of the transcriptions, themes from the data were developed. The data from this study was analyzed using content analysis to search and assess relationships of text with the ability to code specific items for analyses. Open line by line coding of each interview was then applied. 


\section{Quantitative Findings}

\section{General Description of the Sample}

The general demographics of participants are presented in Table 2. Participants were recruited from a community mental health center in Southeastern, Connecticut. They were asked to provide demographic information, such as current age, type of habituation (e.g., private residence without support, private residence with supports, shelter, 24-hour residential program), educational status, and employment status (e.g., unemployed, employed full-time, employed part-time). Participants were also asked to provide information about their current source of income.

Gender. All six of the participants in the study identified as female.

Age. Participants ranged in age from 19 years old to 51 years old.

Race/Ethnicity. Race/Ethnicity. In this study, 3 of participants identified as European/European American. 3 participants identified as African/African American/Black, and 3 identified as Latino(a)/Hispanic.

Habituation. $67 \%$ of participants reported that they lived independently with support, while $17 \%$ reported that they resided with a parent/other relative or with a partner respectively.

Education. $67 \%$ of participants reported that they had attended some high school, while $17 \%$ reported that they had completed high school or achieved a GED. $17 \%$ reported that they had attended some college.

Employment. $17 \%$ of participants reported that they were not employed and that they did not receive any assistance. $17 \%$ reported that they were not employed and that they collected unemployment benefits and $17 \%$ reported that they were not employed and 
they received state assistance. 50\% reported that they were not employed and that they received Social Security Disability (SSD) or Supplemental Security Income (SSI).

\section{Treatment Seeking/Psychiatric Treatment Received}

Participants were asked about the type of psychiatric treatment that they received in the past. $100 \%$ of the participants had received individual therapy. $50 \%$ of participants received group therapy, inpatient hospitalization treatment, outpatient treatment, and substance abuse treatment respectively. 33\% had participated in some form of support group (i.e. AA or NA). $17 \%$ had participated in family therapy and $67 \%$ have received medication management for ongoing mental health concerns.

Frequencies on Structured Clinical Interview for Axis I Disorders (SCID) Items

All participants defined their experience of childhood sexual abuse as a traumatic event in which they experienced, witnessed, or were confronted with a threat to their physical integrity. Additionally, all participants reported that they experienced fear, helplessness, and horror during the time of the sexual abuse. Based on individual examination of each participant's responses to questions on the SCID posttraumatic stress disorder module, all of the participants met Diagnostic and Statistical Manual IV (DSMIV) criteria for PTSD.

Persistent re-experiencing. With regard to re-experiencing the abuse in some way, $17 \%$ endorsed that they thought about the abuse when they did not want to and $83 \%$ reported that they suddenly began thinking about the abuse when they did not want to in the past 6 months. $83 \%$ reported that they had dreams, found themselves acting or feeling as if they were back in the situation, and became upset when something reminded them about the abuse in the past 6 months. $67 \%$ of participants endorsed having physical 
symptoms such as breaking out in a sweat or breathing heavily when something reminded them of the abuse (See Table 12).

Avoidance of stimuli associated with the trauma. All respondents reported that they make a special effort to avoid thinking or talking about what happened, stay away from things or people that remind them of the abuse, and have noticed a change in the way that they think about or pan for the future. $67 \%$ of participants endorsed having difficulty remembering some important part of what happened. $50 \%$ of participants stated that they have much less interest in doing things that used to be important to them, while $50 \%$ reported that this was not true for them. $83 \%$ of participants reported that they have felt distant or cut off from others and $67 \%$ endorsed feeling numb or like they no longer have strong feelings about anything or loving feelings for anyone (See Table 12).

Persistent symptoms of increased arousal not present before the trauma. All participants endorsed having difficulty sleeping and are jumpy or easily startled. $67 \%$ of participants reported feeling unusually irritable and having difficulty concentrating. $83 \%$ of participants reported that they have been watchful or on guard even when there was no reason to be (See Table 12).

\section{Qualitative Findings}

Themes from Semi-Structured Interviews (See Tables 4-11)

Research Question \#I: How do sunivors of CSA describe their experience of disclosure?

$\&$

Research Question \# 2: Who do they disclose to and reasons for selecting this person?

Five of the survivors waited many years to disclose their abuse and one disclosed shortly after the abuse had occurred. Two disclosures happened unexpectedly and four 
were planned. Unpredicted disclosure and trusted disclosure emerged as the two major

themes. For example, Bethany, a 51 year-old survivor whose disclosure was unpredicted says,

Bethany: Well, I told my mother 11 years ago because she was divorcing my father who was the one that had molested me.....I had been planning it for many years.....I was waiting for my mom and that to divorce and cause I was growing up my mom kept saying that she was going to leave him for other reasons because she didn't know what was going on and inside I was like yes, yes, yes. Until finally 11 years ago she said she was leaving him and it was like a relief, I felt like I could finally say something and tell her.

For those survivors who intentionally made a decision to tell someone about their sexual abuse experience, feeling that they could trust someone seemed to be an important factor in helping the survivor to decide disclose their experience. Delores, a 44 year-old survivor specifically talked about trust as a part of her decision to disclose. She stated,

Delores: The main one that I talked to was a case manager...I talked to her about it. It was a long process because I had to make sure that I could trust her.

Flora, a 43-year old survivor shared her experience of disclosing to a counselor after many years of secrecy. She stated,

Flora: I really didn't talk about it until I was in my 20s. Basically, it was suppose to be everything kept in the closet in my family. Nobody needs to know your business. I was taught that if you tell people your business and you tell people what's going on that it makes you weak and they know too much about you so... It was just hush-hush. It happened. It's done with. Leave it alone. Don't bring it up again. That's how it was in my family.

All survivors disclosed to a woman. Three initially disclosed to a close family member (mother, older sister, aunt), two disclosed to a counselor and one to a case manager. One survivor waited nine years before deciding that she could disclose to her case manager because she believed that she could trust her. Delores explained that she 
had to discern whether or not she could trust her case manager before sharing her

experience. She shared,

Delores: Well, I trusted her and that was her line of work so I knew that it would be safe and that it wouldn't go anywhere because it happened when I was a kid and my brother is still out there you know. So, I knew it was ok. I couldn't tell my mom and I always wanted to before she died but I couldn't because my nieces daughter got sexually abused by him and my mom disowned her for 2 years so that scared me and I couldn't tell my mom and I wanted to before she died and I couldn't never do it.

The two survivors who disclosed to their counselors did so in the process of

ongoing therapy many years later. Emily a 45 year-old survivor stated,

Emily: I told one counselor some time ago. It was very hard to say but I decide I have to tell somebody because it's in heart and my mind and everything all the time and I feel bad all the time and I talk to the counselor so I can feel better and I tell her but man, I didn't feel better after the first time. I don't talk about that too much. I feel depressed... down... Sometimes I want to kill myself. I don't know why I feel so bad. I don't feel like I can live with a man because I don't feel nothing. I don't feel like I'm happy with that and I feel like I don't want to get sex with nobody. It's really hard for me.

Flora shared a similar experience of disclosing her trauma history with her counselor. She stated,

Flora: I started going to counseling in my 20s. I couldn't sleep. I couldn't understand why I couldn't sleep or why I kept feeling the way I felt and then, I mostly tried to block it out because nobody in my family wanted to talk about it so it was never brought up again..... my counselor was talking to me one time and was asking me why am I the way I am. She was basically asking me if I had been...you know. And I asked her, "Why would you even bring something up like that to me?" I said, "That's disgusting, why would I have sex with one of my relatives?" They basically told me that what happened to me was not my fault and that I didn't initiate it and that it was not something that I brought on myself that's why it's called abuse. That's why it's called incest.

Bethany told her mother spontaneously in a parking lot after her mother told her

that she planning on divorcing her father. She described the experience stating,

Bethany: Well she was living in another country with him and she came over for vacation in Connecticut and we were walking in the mall in the parking lot and she had said...me and your dad are getting a divorce and I already started the 
paperwork and she asked me how I felt and I said mom, I'm ecstatic, I'm happy and she said well wow and I said yeah, I hated him all my life and she said wow I had no idea I mean why...I said well what is the worst thing that a father can do to a child and she was thinking hard and then she grabbed my arm and she said Oh My God Bethany....and I said yup. She didn't say the words and I said yup.

Angela disclosed one week after the abuse as a result of an aunt overhearing her.

She described her experience stating,

Angela: I didn't decide to tell...My aunt heard me call him a pervert. So...I kind of didn't want to tell her...but, I thought it was right and I told her and my cousin was with me and then she immediately called the cops. And she just flipped on him and then after that they said it was my fault.

Christie, a 43 year-old survivor talked about deciding that she would disclose her

experience with her sister whom she viewed as role model. She says,

Christie: I was scared frightened and I told a family member and then we took it from there ........I told my sister because she raised me. She was more like my role model because my mom worked all the time. I thought she was going to yell and scream but she didn't she just hugged me and we was crying together and um she told me that we was going to be alright.

Research question \# 3: What did survivors hope would happen as a result of disclosure?

Two survivors hoped for some relieffollowing their disclosure.

Bethany: I thought it was gonna be this big relief. It was sort of a relief because it was something I was carrying for 40 something years by myself you know...it was getting heavy... and I just thought it would go away...but it doesn't go away... it will never go away.

Delores: Relief...yeah. I actually I felt like she was my mom for a minute. She hugged me. She held me in her arms like a mom would have done. Like protection.

The other four survivors did not reveal any expectations

Research Question \# 4: What barriers in disclosing did survivors perceive?

When discussing the perceived barriers to disclosing their sexual abuse, they won't believe me, I'll be rejected, and don't disrupt the family emerged as the three major 
categories. Delores stated that she decided not to tell about her experience because, "I didn't think she would believe me." Christie shared that she feared telling someone because her disclosure might be perceived as attention seeking. She shared her experience stating,

Christie: That they wouldn't believe me...that they would think I was longing out for attention cause I'm the baby of the family. But then come to find out that the individual that I told was also being sexually abused too.

Angela, 19 shared that her disclosure was initially taken seriously and then she was later blamed and rejected. She stated, "My aunt said it was my fault...she stopped talking to me and I stopped talking to her."

Two survivors shared the barriers that they perceived to disclosing their sexual abuse. They described their fears about disclosing because they did not want to break up the family unit.

Bethany: ....She would ask "Why didn't you tell me before?" and I didn't want to be the one to break up the family.....Because...we were a family.

Flora: My mother knew, my aunt knew, everybody knew, but it was something that wasn't talked about afterwards. It was in the paper but he never went to jail. He got arrested but my mom didn't press charges because that was her favorite brother and according to her, he didn't mean it because he was drunk.....Family members stop talking to me. When we talked, we talk about everything else but we never talked about that subject again. I knew not to bring it up. It was suppose to stay dead and be dead. They made it seem like it was my fault and that I did something wrong.....And because at the time, I thought I did something wrong. And me being Catholic at the time, I thought to obey my mother and father so...It was like didn't say anything.

Research question \# 5: How do survivors of CSA perceive their disclosure experience?

Angela described her disclosure experience as initially supportive and then it became unsupportive. However, five of the survivors perceived their disclosure experience as positive. 
Bethany: She's like Oh my God, I wish, How could I have not have noticed..."Well mom he didn't do it in public you know." It was supportive.

Christie: I feel I was supported and I was also supported by my mom and um and she would always send me to a baby sitter and not leave me in the house with my father when he was intoxicated. So, and she left him.

Delores: She allowed me to cry. She did hug me afterwards and stayed with me for about 2 hours after. Then she dropped me home and stayed with me until the night time so I felt safe.

Emily: No, she was supportive....A lot.... She tell me that it's not my fault. She tell me that it's not my fault and she tell me that something happened but I have to try to talk about it more cause it hurt me a lot she said or something like that.

Flora: She basically let me know that it wasn't my fault and that um it was never my fault. I didn't do anything wrong. I should never blame myself and that I should never be ashamed of it. Until this day, every counselor that I been to they tell me that I'm a survivor and that I been through a lot in my life and to survive and overcome all that happened to me should make me feel good but it doesn't.

\section{Research Question \# 6: How did survivors react following the response to disclosure?}

\section{Although five of the survivors experienced being supported and cared for}

following their disclosure, they also experienced mixed emotion and regret. Angela was afraid of being rejected by her aunt and this fear became a reality.

Angela: She was really really mad. My cousin wanted to kill him and that was his dad and we were all on the porch and we had my little cousin there and my cousin was telling my cousin was telling my aunt that he did it to our other little cousin too.....Yes, because when I was up there with them on vacation, she said that it acted like everything was fine and then when I came back, she told my mom that she didn't want nothing to do with me.

Bethany somewhat regretted disclosing the abuse as her relationship with the abuser, her father, was severed.

Bethany: ....... I hadn't talked to him in 10 years since I told everyone. My family kept in touch with him...my brothers and sisters kept in touch with him and he remarried... he has a little boy and...he still sort of keeps in touch with my mother and called for birthdays and mother's day which I'm fine with.. That's fine.. Whatever they want to have with him that's fine but I just didn't want 
anything to do with him........I don't know...I feel like the family would have been much closer. My brothers and sisters are still very supportive of me or with me but they did keep a relationship with the father... but not as close as it used to be.

Research Question \# 7: Did the survivors' self-perceived response following disclosure impacting future help seeking and subsequent disclosure?

Based on the responses that survivors provided, it was difficult to discern whether or not the response they received to disclosure impacted their future help seeking behavior in any way. All six of the women who participated in the study were involved in ongoing treatment at the time that the interviews were conducted. Additionally, they had been involved in treatment at some point prior to participating in the study. It is difficult to know if they were engaged in treatment because of their disclosure experience.

Four of the six survivors discussed feeling that getting some type of psychiatric treatment (whether inpatient or outpatient) has been helpful in healing from their sexual abuse experience.

Bethany disclosed to family members 40 years after her initial sexual abuse experience and received a positive response. Bethany recalled that after she disclosed to her mother, that she began disclosing to other family members and her husband shortly after. While she had mixed emotions following her disclosure, she seemed to be supported by her family members. After her family members became aware of her experience, she found herself no longer wanting to talk about the sexual abuse because she wanted to forget that the molestation had ever occurred. She was later admitted to an inpatient treatment facility for depression and expressed ambivalence about receiving psychiatric treatment. Since that time, she has engaged in ongoing psychiatric treatment has found the community mental health center and her therapist to be helpful in her 
healing. While she enjoys the therapeutic atmosphere provided to her by the community mental health center, it became evident through interviewing Bethany that feeling supported by her family was a precipitating factor in her continuing to seeking individual therapy. Below, Bethany recalls being hospitalized involuntarily and her emotional evolution after her hospitalization:

Bethany: I called the cab and came over here to my mother and she said to me, "Why don't you get help?"..."Why don't you talk to a professional? The next day, my son or my sister came with my mom and they brought me to the hospital and I checked into the Pond House and at the same I was glad, at the same time I was nervous for what my kids were going think about me. So I kind of faked that I, was ok to leave so that they would discharge me....Yeah, there were times that I wish I could have gone back since 2008 to 2009 but I need to hold it together for my kids. They have enough to worry about in their life I don't need for them to think or worry about me. It does, actually this whole building (SCSI) and like I've done IOP twice because I enjoy coming here talking.....I've made this place my comfort zone.

Delores, 44 , initially disclosed to her case manager approximately 7 years after the abuse had ended. Delores shared that she did not disclose her sexual abuse experience until she began working with a case manager. After feeling supported by the case manager, she began to seek help for her substance abuse addiction and eventually felt more comfortable disclosing her sexual abuse history. Delores shared during her interview that she has struggled with mental health issues and substance dependence since she was a teenager. She has been in and out of substance abuse rehabilitation facilities since her late 20s. It is probable that she continues to seek help for her addiction because of the positive experience that she had with the case manager. Delores also shared that she has remained in contact with this case manager as she has been supportive to Delores during difficult times in her life. Delores attributes her passions for advocacy around HIV/AIDS related issues and childhood sexual abuse issues are related to her 
early experiences with the case manager. Below, Delores describes feeling supported by the Intensive Outpatient Program and other programs.

Delores: I have a support system, a support network that I talk to and IOP is real a good thing. I go to AA and NA meetings. Yeah. I just came out of rehab for the... I don't know how many times. I went in February 15 ....I only been home for a couple weeks now..... I have been trying to stay clean and stuff and a case manager or someone who cares can really help.

Emily, 45 who also disclosed during the course of treatment has remained fearful of discussing her experience with anyone. After her initial disclosure to her counselor, she decided that she would no longer talk about her experience due to fear that her family might be in danger if anyone found out. Although she did not share her experience with others, Emily continued to talk with her counselor but continues to feel uncomfortable talking about this topic.

While she struggles with hallucinations and depression, she has sought medication management and individual therapy but, has chosen not to divulge any more details of her experiences. Emily explained that she was sexually re-victimized on several occasions since her childhood. While these experiences have made her fearful of being around men and have decreased her overall functioning, it is unclear whether Emily's current engagement in psychiatric services is related to her first positive disclosure encounter with a therapist. She did not explicitly state that she has continued treatment because she perceived her initial disclosure experience as a good one. Below, Emily explained that she does not talk about sexual abuse experience.

Emily: I don't talk to nobody. Cause I very afraid that something could happen to my family or this guy could do something so I live my whole life in fear that something could happen if I say something. I keep my feelings in and everything......No. I just don't want to tell nobody...only her... Because I feel very scared at the time. She say I need to talk about it more but I feel like uncomfortable cause I feel real bad, nervous and everything so I don't want to 
talk about it.........It helped me a lot cause I go talk to her every week...or every two week and she help me. And sometimes I talk about that every time to her and I try to get my feelings out to her. My mind thinking so I feel much better because I think sometimes that I just want to go to my room. I don't want to talk to nobody. No. I don't tell nobody because I very afraid. I afraid so I don't say nothing to nobody.

Similar to Delores and Emily, Flora perceived her first disclosure experience to a therapist in her 20s as positive. After the disclosure to her counselor, Flora reported that she found it hard to talk about what had happened to her because she had difficulty trusting others. Eventually, she decided to confide in a romantic partner who used the information against her. Flora describes her subsequent disclosure experience. She stated,

Flora: I didn't tell anyone. I had no friends. People who knew me, who were my friends were also friends with my family so I couldn't tell them. I didn't talk about it with them because if I was to say something to them, they would have brought it back and said something to my family that I'm still talking about it so it stayed dead and buried. I got married at an early age because number one, I was Catholic and I was pregnant so I got married. But I mostly kept everything to myself so my husband didn't know anything either. The only person that knew that it happened was somebody that I was with some time ago. I was able to...he was my best friend. I could talk to him about anything. But, we went our separate ways and he is still my best friend but sometimes, you think people look at you different and then you get those people that have weird fantasies and fetishes like, "Let's make pretend I'm raping you." That's supposed to turn them on and it's not a turn on.

Although Flora has had some negative experiences with disclosure, she finds that talking with a counselor is helpful in her healing process. When asked who supports her emotionally, Flora says, "Jenn...My counselor...Other than that, I don't got nobody in my corner."

Angela, 19 disclosed 1 week after she was sexually molested by her uncle. Her disclosure was initially met with support and was later met with skepticism. Angela is currently receiving ongoing therapy. Angela's experience of disclosure was mixed and it 
is difficult to assume a causal relationship between the response to disclosure that she received and her help seeking behavior.

Christie, 44 delayed disclosed until 3 years after the initial abuse because she was planning how she would tell and to whom she would disclose. She shared during the interview that she is currently receiving group therapy as a part of continuation of care following her discharged from an inpatient hospitalization for mental health issues and substance dependence. Prior to this hospitalization, Christie had not sought psychiatric treatment, possibly indicating that Christie may not have sought treatment for her issues if she was not transitioned to an after care facility by the psychiatric hospital.

Research Question \# 8: What suggestions would a survivor of CSA give to clinicians, teachers, and parents regarding disclosure of CSA?

Three of the survivors made a strong recommendation that anyone who is abused should, "tell someone." The women who strongly encouraged disclosure soon after being sexually molested felt that their life circumstances might be somewhat different if they had disclosed sooner. Bethany who disclosed to her mother stated,

Bethany: It's painful, it's horrible...I think by knowing it and helping that person in the early stage...things might be different as they get older. I think getting or letting assuring the child, keep reminding the child that it is ok to speak out. As they keep reminding people that cigarettes give cancer, wear your seatbelt everywhere that should be told to kids at an early age because a child sees things differently. They're more innocent. That's why sometimes when I look at a child it is very hard, especially a very young child. Their smile is so pure. Their eyes are still clear. They have a glow to their eyes and just like that somebody can come and take it away. They don't quite feel how horrible it is while they're growing up but it starts to eat at you little by little because you're still hoping or wishing it didn't happen or setting it aside while it is still picking at you.

Christie who disclosed to her sister stated, 
Christie: Just tell someone. It don't matter who, just tell someone because when you keep letting it go on, it haunt you even more.

Flora did not disclose her sexual abuse until she was in her 20 s to a counselor also

strongly suggested disclosure. She stated,

Flora: One, they'll be able to talk to someone about it and get it out in the open and share what happened. When the person is understood... There is no faking. There's no faking being molested. Once they start talking and explaining the situation, there is no way the person is not going to believe that child aint been raped. There is no faking being raped. If you can't talk to your parents, talk to a friend's mother. Talk to a teacher. If I had somebody to talk to..I probably would have been different till this day. I probably wouldn't have been so easily swayed. I would have believed in my dreams. I would have believed in myself. My grandma kept me alive because I had someone that loved me unconditionally. When she looked at me, she looked at me and loved me unconditionally. Talk to a teacher, a friend, you're better off getting support from a stranger than your family. I tell my daughter's best friend that if she ever needs me to talk to her about anything, my door is always open. If I could turn time back, if there was a teacher I could have talked to or somebody instead of listening to what my mother said, I could have finished school. I could have done everything I wanted to do and not cared about anything. 


\section{Discussion}

Previous literature on disclosure of childhood sexual abuse has a noticeable shortcoming in that there has been little or no research that examines whether disclosure experience affects future help seeking behaviors. The literature on victim reporting tends to focus on obstacles to disclosure and on the consequences of disclosure to the victim, rather than on the process of disclosure itself (Browne, 1991). The current study differs from other studies on disclosure of CSA because it focused on the process of disclosure and explored whether response to disclosure impacted future help seeking behaviors for survivors.

\section{Salient Themes in Survivors' Disclosure of Childhood Sexual Abuse?}

Barriers to disclosure. According to studies conducted by Sommer and Szwarcberg (2001), and Alaggia (2004), it was noted that feeling helpless was a major factor that inhibited CSA disclosure. This research finding was consistent with the current study as all six survivors reported that they felt helplessness at the time of their abuse. However, none of the survivors specifically indicated that feeling helpless was a barrier to disclosure. Survivors shared that they felt overwhelmed by shame and guilt that they had "allowed" the sexual abuse to occur.

Three major themes emerged as barriers to disclosure. "They won't believe me," "I'll be rejected," and "don't disrupt the family" were salient among all six survivors. All of the women in the study relayed that they perceived loyalty to the family as important to them delaying their disclosure. They all feared that their disclosure would be met with skepticism, disbelief, and that family members would not believe them because (1) the alleged perpetrator resided within the household and (2) the reported abuser was close to 
the family, rather than an unfamiliar perpetrator. One survivor explained that she delayed disclosure because she believed that her family members would think that she was attempting to gain attention because she is the youngest in her family. Another survivor did not disclose willfully due to fear that she would not be believed. When she finally decided to tell her family members, her disclosure was met with support. Later, it was met with incredulity and disbelief because the perpetrator was a member of her extended family.

The findings from the current study are similar to findings in the literature about barriers to disclosure. Studies conducted on survivors' experiences highlight that many survivors decide not to disclose at all or delay disclosure due to fear that they will be rejected or because they feel that their story will somehow disrupt the family unit. One survivor explained that things that happened within the family should stay in the family. It would make sense that some survivors chose not to disclose CSA if they are from families or communities in which allegiance to the family is sacred. Similar to fear of disrupting the family unit, several survivors in this study mentioned that they delayed disclosure due to fear that members in the community would find out. They feared embarrassment and being perceived as "weak" if members of the community found out what happened.

Survivors' perceived barriers to disclosure are interesting considering that another major theme that emerged when asked about what a child should do when they have been sexually molested was "tell someone." It is interesting that most survivors in this study delayed disclosure for several reasons; however they, three survivors made a strong recommendation that any child that is being sexually abused should not postpone 
disclosure. Instead, they strongly encourage children who are experiencing any form of sexual abuse to tell someone early on so that something can be done about it. They all felt that their life circumstances may have been different if they had disclosed sooner. One survivor recommended that there should be more advocacy around childhood sexual abuse so that children feel empowered to tell someone. She thought that advocacy could be achieved through ads similar to the ads that say "cigarettes cause cancer." It is possible that this paradox exists because survivors are now able to see that early disclosure can be beneficial. Thus, they recommend that others should not do as they did because telling someone may have result in fewer long term implications.

While all of the survivors acknowledged the negative impact that their sexual abuse experience had on their lives. Three specifically gave specific suggestions about how teachers, clinicians, and parents should respond when faced with a disclosure of sexual abuse. Most survivors shared that they thought persons who are disclose to should offer unconditional support because support can be very empowering.

Unpredicted disclosure and trusted disclosure. Survivors recognized that disclosure could have negative implications for themselves and for their family. For this reason, survivors reported delaying disclosure until they felt that they could tell someone whom they deemed as trustworthy. Unpredicted disclosure and trusted disclosure emerged as two salient themes. Those survivors who had trusted disclosure explained that whether it was a family member or therapist that they needed to feel that they had faith in the person to whom they were disclosing their experience. Even for those survivors whose disclosure was unpredicted, they also needed to feel that they could trust the 
person that they were telling and there were not many perceivable negative consequences to their disclosure.

All survivors in the current study disclosed to a woman. The theme of trust has emerged in other research studies on disclosure of childhood sexual abuse. These studies have indicated that 2 major factors associated with disclosure are that survivors need to feel supported and protected. Gries et al., (2000) and Sinclair (1999) explain that parental, especially maternal support following disclosure buffers against the harmful effects of sexual abuse and promotes the victims' emotion and psychological adjustment. Only one survivor disclosed to her mother after approximately 40 years of keeping her sexual abuse experience a secret. Her disclosure was unpredicted and came shortly after she felt that it would be safe to disclose because there were perceivably less consequences since her parents were getting a divorce and the perpetrator was her father. She noted that she primarily did not share her CSA history prior to knowledge of the divorce due to fear that she would break up the family unit. For survivors who disclosed to a counselor, they discussed feeling that having maternal support would have been valuable. One survivor explained that if she had her mother's support that her life trajectory may have been somewhat different.

Survivors' hopes following disclosure. Two survivors relayed that they felt relieved following their disclosure because they were feeling burdened by the fact that they had been sexually exploited. One survivor noted that she felt relief and protection. Although these survivors initially felt relieved, both women explained that the relief that they felt was short-lived because they are always disturbed by memories of experience. All of the survivors noted that whether they disclosed to someone they trusted or whether 
their disclosure was unpredicted, they felt that the memory of what they experience would never go away. All of the survivors indicated that they continue to be haunted by their sexual abuse experience in some way many years after the incident(s). They experience intrusive thoughts when they do not want to think about what happened and they continue to be bombarded with memories of the horrific event(s) that they experienced. For this group of six women, disclosing their sexual abuse experience did not lead to long-term relief or an amelioration of PTSD related symptoms.

Perceived response to disclosure. Survivors typically described their disclosure experience as positive when they felt that they were supported. It appears that being allowed to cry and openly express emotions was not only cathartic, but it also helped survivors to feel that their experiences were being validated. Additionally, being told that the abuse was not their fault contributed to survivors perceiving their disclosure experience as a positive one. It is important to note that although many of the survivors felt supported after their disclosure, most survivors also experienced mixed emotions. A supportive response was also coupled with feelings of regret, guilt, and shame.

Disclosure was often also followed by feeling conflicted about having potentially jeopardized family relationships. These survivors have highlighted that although disclosure can be liberating, that it can sometimes comes with harsh consequences, not only for the survivor but also for the families of survivors as well. Not only is the character of the survivor questioned but, the character of the abuser is also questioned particularly if the perpetrator is close to the family and is well liked. This theme is consistent throughout the literature on sexual abuse. 
Future help seeking. Findings from the study indicate that a positive response to disclosure may not be the only determinant of future help seeking behavior as was previously thought. This study highlights that feeling supported is significant. In fact, support may serve as a buffer against some of the deleterious outcomes commonly associated with sexual trauma history. It appears that having strong family support from a maternal figure, a sense of belonging in the family, and having the perpetrator punished in some way seemed to be important aspects of the disclosure experience. Survivors explained that the abovementioned factors served as a protective factor against engaging in some of the negative behaviors linked to CSA (i.e. prostitution, substance abuse). Although the survivors who reported that feeling supported in various ways deterred them from engaging in risky behaviors, survivors report that they continue to experience negative emotional outcomes as a result of their early sexual trauma (i.e. depression, suicidal ideation). This implies that support may prevent some outcomes, but that the emotional implications for sexual trauma survivors are long-lasting despite the structures in place. This reinforces what is already known about the devastating effect of CSA. However, there may be things that can be done to ameliorate some of the negative consequences associated with being traumatized.

It is important to note that all of the survivors in this small sample were recruited from a community mental health center and are all receiving ongoing treatment therefore, it was difficult to determine whether or not the response to disclosure impacted future help seeking because three of the six women disclosed to a case manager or counseling during the course of ongoing therapy several years after the sexual abuse had occurred. Survivors may have actively sought treatment but, it is unclear whether or not their 
treatment seeking was prompted by desire to discuss their sexual abuse history. Since their time at the community health center, all of these survivors in the study had disclosed their CSA history. Although they are all actively connected with mental health services, most reported that they chose not to disclose their CSA history following their initial disclosure. Although their treatment seeking history is somewhat unclear.

Childhood sexual abuse and psychological sequalae. Findings from this study revealed that survivors who were sexually abused by a close family member had more negative emotional and behavioral outcomes. All of the women who experience sexual abuse by a close family member shared that they have since experienced depression, problems with substance abuse/dependence, and have engaged in risky sexual behavior (i.e. sexual promiscuity and prostitution).

The findings from this study were consistent with findings from previous studies conducted with survivors of CSA which states that CSA has a wide number of psychological sequelae (Classen et al., 2005; Boney-McCoy \& Finkelhor, 1998; Nagel et al., 1997). Among these are low self-esteem, anxiety, depression, anger and aggression, post- traumatic stress, dissociation, substance abuse, sexual difficulties, somatic preoccupation and disorder (particularly, pseudo seizures, pelvic pain, and gastrointestinal disturbances), self-injurious or self-destructive behavior. Matsakis (1991) found that children who have been sexually abused by a relative are more likely to suffer from depression and self-destructive than children who have been sexually assaulted by a stranger.

This study revealed that all six survivors met diagnostic category for PTSD whether or not the abuse was a onetime occurrence or more ongoing. This finding aligns 
with studies such as Brewin and colleagues' (2000) study which indicate that survivors of sexual abuse suffer long term negative consequences of their experiences. , It is conceivable that the women in the study all endorsed symptoms associated with PTSD as they were actively involved in the traumatic events rather than merely a witness. Being more actively involved in traumatic events has been linked with more dysfunctional response $\mathrm{s}$ (Book).

As discussed in previous studies on risk factors for PTSD in trauma exposed individuals (Brewin et al. (2000), this study underscores that psychosocial risk factors such as younger age at the time of the trauma exposure, female gender, lower SES, lower education, lower intelligence, and minority racial/ethnic status are preexisting characters that make a trauma victim more likely to develop PTSD related symptoms.

Data collected was from a relatively homogenous sample of women. With regard to age of when the sexual abuse occurred, five of the six women were under the age of 8 when the sexual abuse occurred. One woman was 11 years old when she was sexually abused. The majority of survivors had only received a high school education or less and earned less than $\$ 10,000$ per year. All survivors received some form of government assistance. Four of the six women belonged to minority racial groups. They all resided in low-income neighborhoods in Southeastern, CT and have limited financial resources. Through information gathered from their interviews, four women indicated family instability and poor family functioning prior to and after the abuse. It is plausible that all of these factors serve as risk factors to their current PTSD symptomatology.

Childhood sexual abuse and sexual functioning. Significant associations have been documented between childhood sexual abuse and risky sexual behaviors (Wyatt et 
al., 2002). Some researchers have suggested a "continuum of victimization" exists, with early abuse experiences being associated with greater sexual risks, including re victimization (Wyatt et al., 2002). It appears that CSA also greatly impacts adult psychosexual functioning. Loeb et al. (2002) suggest that sexual victimization as a child may have an impact on adult female sexuality by impairing sexual decision making, sexual behaviors, and risk taking. Based on developmental theory (Hughes, 2000), it can be assumed that adolescent and adult functioning are greatly affected by prior sexual development.

This study also highlighted that sexual re-victimization is common among women who were victimized as children. Survivors spoke of being re-victimized during their adulthood on more than one occasion. This finding is in line with studies which proffer that childhood sexual abuse (CSA) doubles or even triples the risk of sexual victimization for adults (Classen et al., 2005). 


\section{Current Study Limitations}

This study had several limitations. Firstly, the questions for the interview needed to be more refined in order to elicit certain responses about help seeking behaviors. There was no pilot interview conducted. Conducting a pilot interview may have yielded more information about questions that needed to be revised/rephrased. Furthermore, a pilot interview may have revealed questions that may be perceived as unclear, ambiguous, and confusing to participants. For example, during the interviews it became evident that the word 'disclosure' caused some confusion for participants. Some participants seemed unclear about the definition of the word and the questions that included the word disclosure had to be reworded spontaneously by the interviewer. Rephrasing questions to meet the needs of each participant has advantages and disadvantages. Advantages of rephrasing are that the questions were made less ambiguous and more understandable. However, one of the clear disadvantages of rephrasing questions for each interview is that the interviews lacked consistency and therefore yielded different responses from each participant.

A second limitation of the current study is that the women were engaged in ongoing treatment. Many of the women had been in and out of treatment facilities over the course of their lifetime for issues not pertaining to their trauma history. It is plausible that if these participants were not recruited from a treatment facility that the interviews may have yielded more information about their treatment seeking history related to their trauma experience. Since the purpose of the study was to determine the relationship between disclosure and help-seeking it probably was not a good idea to include women who disclosed after help-seeking. Eligibility criteria should also been explicit about 
treatment seeking history. It should have been required that the disclosure not have been first to a counselor.

Thirdly, the sample is one of highly traumatized survivors and is not representative of all child sexual abuse survivors. Conducting a study with women who have varying trauma histories may yield more fruitful findings. For example, a survivor may feel differently about her abuse experience if she was a survivor of exhibitionism than a survivor that experienced penetration and exhibitionism. Nonetheless, all forms of childhood sexual abuse are traumatizing, however it might be helpful to understand the experiences of women with different types of trauma and how they describe their disclosure process.

\section{Recommendation for Clinicians}

As previously noted, disclosure of sexual abuse can be a difficult experience regardless of the survivors' stage in the healing process. For clinicians working with survivors of sexual abuse, it is important to allow survivors to decide when they feel comfortable enough to fully disclosure their sexual abuse experience. Feeling forced or not feeling entirely ready to disclose can lead to feeling regret that they opened up about their experience. Although the feeling of regret following disclosure may be the case even if the survivor did not feel pressured to talk about her experience, it is important to respect as little or as much as the survivor feels comfortable disclosing. Creating an environment or space in which the survivor feels safe to genuinely and openly discuss how they felt following the disclosure is pivotal.

Throughout the disclosure process that may occur over the course of many sessions, clinicians should try to assess if the survivor felt judged or criticized. Did the 
survivor feel shamed in any way? Discussion should also be had around whether or not the survivor felt that they shared too much about their past experience. When dialogue can be created about such issues, this can lead to survivors feeling empowered by being able to express their feelings.

Survivors may wonder what they will gain by disclosing and it is important to create meaningful dialogue with each survivor about their potential gains from disclosure. The gains from disclosure may not be evident to all survivors however; being able to share some information about a sexual abuse experience with a clinician can increase validation and affirmation. If the therapeutic relationship is authentic, survivors may experience increased self awareness and identity formation. One of the overall goals of the therapeutic relationship should be to increase intimacy as many survivors struggle to maintain close, intimate relationships. Even if a survivor disclosed about being sexually abused and indicates in some way that they may have felt shame or regret after sharing, the therapist should continue to build the therapeutic alliance as this may lead to growth in the long term.

Implications and Future Directions for Research

This study explored the impact of positive/negative response to disclosure on future help seeking. Future studies should explore the role of support in future help seeking as support may be a better predictor of future help seeking among women who have been sexually abused. Of course, support would need to be more clearly defined. Also, future studies should explore the role of support in behavioral and emotional outcomes for CSA survivors. 
It is important to note that the way an adult responds to partial disclosures, accidental disclosures, or indirect disclosures may be critical to whether a child will tell further. Thus, when these disclosures are made, not only is the initial reaction important, but so is the response of adults who subsequently learn of the information and confront the child. As shown in this study, an adult's response is important. However, a positive response coupled with support seems to be of critcial importance.

There is no simple solution to the problem of childhood sexual abuse and the process of disclosure however, small societal steps that can be taken to provide support to survivors while helping them to maintain family relationships. This would require people not turning a blind eye to abuse that is suspected or actual. Additionally, it would require that the survivor take actual steps to disclose the abuse to someone despite the numerous consequences associated with disclosure (particularly if the perpetrator is a member of the family). Disclosure is almost always an ongoing process. It may begin with an initial, quite dramatic first step, or it may manifest itself as a series of tentative revelations, hints, and explorations. Either way, the act of disclosure frequently sets in motion interactiosn with service providers, authorities and others, and the process of intervention may stretch on through month or even years of survivors' lives. Survivors must chose to pursue this pathm or at least agree to participate. At some points in the process, there are steps of initiation that only the survivor can take, although others may stand with suggestions and support. With this said, there should be societal steps taken to assist in helping survivors to feel more empowered that they can disclose and that they will be supported. Settings such as schools should garner an environment that is welcoming and supportive of survivors' claims of sexual abuse. Claims should not be met with skepticism or 
uncertainity. Questioning whether the survivor's claims are accurate or victim blaming could decrease the likelihood that the survivor will follow through with their claims.

For survivors to follow a course of actions successfully, it is most helpful if the path is already established--prepared for their use by advocates and service providers. It is society's responsibility to prepare different avenues for a survivor to feel comfortable and supported, to make them know, and to maintain them.

When thinking about what can be done to solicit survivors to come forward about their abuse experience, it begins with making the public aware of the paths that exist for disclsoure and intervention. Survivors need to know that they have options and this can be communicated through avenues such as the media and community organizations. The survivor can then chose the way in which they feel most comfortable disclosing. The second step would involve making sure that when a survivor does disclose their abuse that they are not left not knowing what the next step in the process will be. Leaving a survivor "in the dark" continues the cycle of victimization and may add to feelings of powerlessness. Instead, a survivor should be actively involved in the disclosure process as they feel comfortable doing so. This increases the survivors sense of feeling empowered and that they have control of what happens to them. This is often not the case when they are being victimized. While they may not feel entirely comfortable with the process, they should be encouraged along the way and constantly asked what feels comfortable/uncomfortable. They need constant reassurance that the steps they are taking are right as the survivor may feel guilty for coming forward.

It should also be the responsibility of society to make the pathways for assistance and relief free of obstacle and confusion. Feeling confused and uninformed can lead to 
feeling uncertain about the process. It is the goal to help the survivor feel confident and having streamlined procedures and clear directions for how to move forward in the disclosure process is absolutely pivotal. As previously discussed, feeling supported is extremely important. It might be helpful to have the survivors be walked through the process by other survivors and advocates.

It is important to remember the process of disclosure is not a linear one. It should be understood that survivors will sometimes disclose and then recant their disclosure due to factors such as family pressure and loyalty to the family. It is society's obligation to make sure that avenues of support remain open and unobstructed to accommodate survivors as they vacillate between disclosing and silence. It is society's responsibility to reamin open, non judgmental, and unbiased to survivors who need to retrace their steps several times before moving forward. 
Appendix I

Demographic Information and Qualitative Findings 
Table 1. Age of Sexual Abuse, Type of Sexual Abuse, Perpetrator, and Disclosure Information

\begin{tabular}{|c|c|c|c|c|}
\hline Angela & $\begin{array}{c}\text { Current } \\
\text { Age }\end{array}$ & $\begin{array}{c}\text { Age when } \\
\text { abused }\end{array}$ & Type of Abuse & Perpetrator \\
\hline Bethany & 51 & 7 years old & Touching/Fondling & Uncle \\
\hline Christie & 43 & Did not disclose & Touching/Fondling/Exhibitionism & Biological Father \\
\hline Delores & 44 & $5-18$ years old & Penetration/Exhibitionism & Biological Brother \\
\hline Emily & 45 & Multiple time & Touching/Fondling/Penetration & Multiple \\
periods & & & Touching/Fondling/ \\
\hline Flora & 43 & 11 years old & Touching/Fondling/Penetration & Uncle \\
\hline
\end{tabular}


Table 2. Type of Disclosure and Perceived Disclosure Experience

\begin{tabular}{|c|c|c|c|c|}
\hline & $\begin{array}{c}\text { Type of } \\
\text { Disclosure }\end{array}$ & Disclosed & Disclosed to & $\begin{array}{l}\text { Perceived Self Disclosure } \\
\text { Experience }\end{array}$ \\
\hline Angela & Unpredicted & 1 week later & Aunt & $\begin{array}{l}\text { Supportive/Unsupportive } \\
\text { Disclosure }\end{array}$ \\
\hline Bethany & Unpredicted & 40 years later & Mother & Supported \\
\hline Christie & Trusted & 3 years later & Sister & Supported \\
\hline Delores & Trusted & $\begin{array}{l}\approx 25 \text { years } \\
\text { later }\end{array}$ & $\begin{array}{c}\text { Case } \\
\text { manager }\end{array}$ & Supported \\
\hline Emily & Trusted & $\begin{array}{l}\text { As an adult } \\
\text { (exact age } \\
\text { unknown) }\end{array}$ & Counselor & Supported \\
\hline Flora & Trusted & During 20s & $\begin{array}{l}\text { Mother } \\
\text { Grandmother } \\
\text { Counselor }\end{array}$ & $\begin{array}{l}\text { Unsupported by mother } \\
\text { Supported by grandmother } \\
\text { Supported by counselor }\end{array}$ \\
\hline
\end{tabular}


Table 3. Demographic Information

\begin{tabular}{|l|c|}
\hline \multicolumn{1}{|c|}{ Demographic Information } & $\begin{array}{c}\text { \% of } \\
\text { Survivors }\end{array}$ \\
\hline Race/Ethnicity & \\
European/European American & $33.3 \%$ \\
African/African American/Black & $33.3 \%$ \\
Latino(a)/Hispanic & $33.3 \%$ \\
& \\
\hline Habituation & \\
Independently w/support & $66.7 \%$ \\
With a parent or other relative & $16.7 \%$ \\
With a partner & $16.7 \%$ \\
& \\
\cline { 2 - 2 } & \\
\hline Education & $66.7 \%$ \\
Some High School & $16.7 \%$ \\
Completed high school or GED & $16.7 \%$ \\
Some college & \\
& \\
\hline Employment & \\
No, Not employed and I do not receive benefits & $16.7 \%$ \\
No, Not employed and I collect unemployment & $16.7 \%$ \\
No, Not employed and I receive SSD or SSI & $50 \%$ \\
No, Not employed and I receive state assistance & $16.7 \%$ \\
& \\
& \\
\hline Income & \\
\$0 to \$10,000 & \\
\$10,000 to \$19,000 & \\
& \\
\hline
\end{tabular}


Table 4. Type of Psychiatric Treatment

\begin{tabular}{|c|c|}
\hline $\begin{array}{l}\text { Type of Psychiatric } \\
\text { Treatment Received }\end{array}$ & $\%$ of Survivors \\
\hline Individual therapy & $100 \%$ \\
\hline Group therapy & $50 \%$ \\
\hline Support groups & $33 \%$ \\
\hline Family therapy & $17 \%$ \\
\hline Medication & $67 \%$ \\
\hline Inpatient hospitalization & $50 \%$ \\
\hline Outpatient treatment & $50 \%$ \\
\hline \multirow[t]{2}{*}{$\begin{array}{c}\text { Substance abuse } \\
\text { treatment }\end{array}$} & $50 \%$ \\
\hline & Type of Treatment Received \\
\hline Angela & $\begin{array}{c}\text { Individual Therapy } \\
\text { Medication } \\
\text { Inpatient Hospitalization } \\
\text { Outpatient Treatment } \\
\end{array}$ \\
\hline Bethany & Individual Therapy \\
\hline Christie & $\begin{array}{c}\text { Individual Therapy } \\
\text { Group Therapy } \\
\text { Medication } \\
\text { Outpatient Treatment } \\
\text { Substance Abuse Treatment }\end{array}$ \\
\hline Delores & $\begin{array}{c}\text { Individual Therapy } \\
\text { Group Therapy } \\
\text { Support Groups } \\
\text { Medication } \\
\text { Inpatient Hospitalization } \\
\text { Outpatient Treatment } \\
\text { Substance Abuse Treatment }\end{array}$ \\
\hline Emily & $\begin{array}{c}\text { Individual Therapy } \\
\text { Support Groups } \\
\text { Medication } \\
\text { Inpatient Hospitalization } \\
\text { Substance Abuse Treatment }\end{array}$ \\
\hline Flora & $\begin{array}{l}\text { Individual Therapy } \\
\text { Group therapy } \\
\text { Medication } \\
\text { Inpatient Hospitalization } \\
\end{array}$ \\
\hline
\end{tabular}


Table 5. Survivor Responses to Research Questions 1 and 2

\begin{tabular}{|c|c|}
\hline & $\begin{array}{l}\text { How do survivors of CSA describe their experience of disclosure? And Who did } \\
\text { they disclose to and reasons for selecting this person? }\end{array}$ \\
\hline Angela & $\begin{array}{l}\text { I didn't decide to tell...My aunt heard me call him a pervert. So...I kind of didn't } \\
\text { want to tell her...but, I thought it was right and I told her and my cousin was with } \\
\text { me and then she immediately called the cops. And she just flipped on him and } \\
\text { then after that they said it was my fault. }\end{array}$ \\
\hline Bethany & $\begin{array}{l}\text { Well, I told my mother } 11 \text { years ago because she was divorcing my father who } \\
\text { was the one that had molested me.....I had been planning it for many years.....I } \\
\text { was waiting for my mom and that to divorce and cause I was growing up my } \\
\text { mom kept saying that she was going to leave him for other reasons because she } \\
\text { didn't know what was going on and inside I was like yes, yes, yes. Until finally } \\
11 \text { years ago she said she was leaving him and it was like a relief, I felt like I } \\
\text { could finally say something and tell her. }\end{array}$ \\
\hline Christie & $\begin{array}{l}\text { I was scared frightened and I told a family member and then we took it from there } \\
\text {........I told my sister because she raised me. She was more like my role model } \\
\text { because my mom worked all the time. I thought she was going to yell and scream } \\
\text { but she didn't she just hugged me and we was crying together and um she told me } \\
\text { that we was going to be alright. }\end{array}$ \\
\hline Delores & $\begin{array}{l}\text { The main one that I talked to was a case manager...I talked to her about it. It was } \\
\text { a long process because I had to make sure that I could trust her. }\end{array}$ \\
\hline Emily & $\begin{array}{l}\text { I told one counselor some time ago. It was very hard to say but I decide I have to } \\
\text { tell somebody because it's in heart and my mind and everything all the time and I } \\
\text { feel bad all the time and I talk to the counselor so I can feel better and I tell her } \\
\text { but man, I didn't feel better after the first time. I don't talk about that too much. I } \\
\text { feel depressed...down...Sometimes I want to kill myself. I don't know why I feel } \\
\text { so bad. I don't feel like I can live with a man because I don't feel nothing. I don't } \\
\text { feel like I'm happy with that and I feel like I don't want to get sex with nobody. } \\
\text { It's really hard for me. }\end{array}$ \\
\hline Flora & $\begin{array}{l}\text { I really didn't talk about it until I was in my 20s. Basically, it was suppose to be } \\
\text { everything kept in the closet in my family. Nobody needs to know your business. } \\
\text { I was taught that if you tell people your business and you tell people what's going } \\
\text { on that it makes you weak and they know too much about you so...It was just } \\
\text { hush-hush. It happened. It's done with. Leave it alone. Don't bring it up again. } \\
\text { That's how it was in my family. }\end{array}$ \\
\hline
\end{tabular}


Table 6. Survivor Responses to Research Question 3

\begin{tabular}{|c|l|}
\hline Angela & \multicolumn{1}{|c|}{ What did survivors hope would happen as a result of the disclosure? } \\
\hline Bethany & $\begin{array}{l}\text { I thought it was gonna be this big relief. It was sort of a relief because it was } \\
\text { something I was carrying for } 40 \text { something years by myself you know...it was } \\
\text { getting heavy...and I just thought it would go away... but it doesn't go away...it } \\
\text { will never go away. }\end{array}$ \\
\hline Christie & $\begin{array}{l}\text { I thought she was going to yell and scream but she didn't she just hugged me and } \\
\text { we was crying together and um she told me that we was going to be alright. }\end{array}$ \\
\hline Delores & $\begin{array}{l}\text { Relief...yeah. I actually I felt like she was my mom for a minute. She hugged me. } \\
\text { She held me in her arms like a mom would have done. Like protection. }\end{array}$ \\
\hline Emily & $\begin{array}{l}\text { I didn't feel better after the first time. I don't talk about that too much. I feel } \\
\text { depressed..down..Sometimes I want to kill myself. I don't know why I feel so } \\
\text { bad. I don't feel like I can live with a man because I don't feel nothing. I don't } \\
\text { feel like I'm happy with that and I feel like I don't want to get sex with nobody. } \\
\text { Um..It's really hard for me. }\end{array}$ \\
\hline Flora & $\begin{array}{l}\text { I thought she was going to look at me funny or look at me like I was dirty. Till } \\
\text { this day, my aunt will come to me and she'll say, "You know Flora, people still } \\
\text { come to me and say you remember that time you found your niece on the couch } \\
\text { overdosed on medication." They don't remember anything else but they } \\
\text { remember something I did when I was } 16 \text { years old. Regardless, me still here, me } \\
\text { 43 years old, people still go to my aunt and remember incidents like that, but they } \\
\text { don't remember what happened to me. My aunt was the one that called the police } \\
\text { cause she was babysitting me at the time. }\end{array}$ \\
\hline
\end{tabular}


Table 7. Survivor Responses to Research Question 4

\begin{tabular}{|c|c|}
\hline & What barriers in disclosing did survivors perceive? \\
\hline Bethany & $\begin{array}{l}\text {...She would ask "Why didn't you tell me before?" and I didn't want to be the } \\
\text { one to break up the family.....Because... we were a family. }\end{array}$ \\
\hline Christie & $\begin{array}{l}\text { That they wouldn't believe me...that they would think I was longing out for } \\
\text { attention cause I'm the baby of the family. But then come to find out that the } \\
\text { individual that I told was also being sexually abused too. }\end{array}$ \\
\hline Delores & I didn't think she would believe me \\
\hline Emily & $\begin{array}{l}\text { Cause people not gonna believe me. He don't want me to say nothing because } \\
\text { then something could happen to me. Cause he's a very bad boy. I don't like him } \\
\text { at all. And I feel very afraid. I afraid of men now. I don't feel I can live with men } \\
\text { now no more. I can't do sex with men. }\end{array}$ \\
\hline Flora & $\begin{array}{l}\text { Family members stop talking to me. When we talked, we talk about everything } \\
\text { else but we never talked about that subject again. I knew not to bring it up. It was } \\
\text { suppose to stay dead and be dead. They made it seem like it was my fault and that } \\
\text { I did something wrong. }\end{array}$ \\
\hline
\end{tabular}


Table 8. Survivor Responses to Research Question 5

\begin{tabular}{|c|c|}
\hline & $\begin{array}{l}\text { How do survivors of CSA perceive their disclosure experience (e.g., } \\
\text { positively or negatively, supportive, unsupportive }\end{array}$ \\
\hline Angela & $\begin{array}{l}\text { So...I kinda didn't want to tell her...but, I thought it was right and I told } \\
\text { her and my cousin was with me and then she immediately called the cops. } \\
\text { And she just flipped on him and then after that they said it was my fault. }\end{array}$ \\
\hline Bethany & $\begin{array}{l}\text { She's like Oh my God, I wish, How could I have not have noticed..."Well } \\
\text { mom he didn't do it in public you know." It was supportive. }\end{array}$ \\
\hline Christie & $\begin{array}{l}\text { I feel I was supported and I was also supported by my mom and um and she } \\
\text { would always send me to a baby sitter and not leave me in the house with } \\
\text { my father when he was intoxicated. So, and she left him. }\end{array}$ \\
\hline Delores & $\begin{array}{l}\text { She allowed me to cry. She did hug me afterwards and stayed with me for } \\
\text { about } 2 \text { hours after. Then she dropped me home and stayed with me }\end{array}$ \\
\hline Emily & $\begin{array}{l}\text { No, she was supportive....A lot.... She tell me that it's not my fault. She } \\
\text { tell me that it's not my fault and she tell me that something happened but I } \\
\text { have to try to talk about it more cause it hurt me a lot she said or something } \\
\text { like that. }\end{array}$ \\
\hline Flora & $\begin{array}{l}\text { She basically let me know that it wasn't my fault and that um it was never } \\
\text { my fault. I didn't do anything wrong. I should never blame myself and that } \\
\text { I should never be ashamed of it. }\end{array}$ \\
\hline
\end{tabular}


Table 9. Survivor Responses to Research Question 6

\begin{tabular}{|c|c|}
\hline & How did survivors react (e.g., behaviors) following the response to disclosure? \\
\hline Angela & $\begin{array}{l}\text { She was really really mad. My cousin wanted to kill him and that was his dad and } \\
\text { we were all on the porch and we had my little cousin there and my cousin was } \\
\text { telling my cousin was telling my aunt that he did it to our other little cousin } \\
\text { too.....Yes, because when I was up there with them on vacation, she said that it } \\
\text { acted like everything was fine and then when I came back, she told my mom that } \\
\text { she didn't want nothing to do with me }\end{array}$ \\
\hline Bethany & $\begin{array}{l}\text {...... I hadn't talked to him in } 10 \text { years since I told everyone. My family kept in } \\
\text { touch with him...my brothers and sisters kept in touch with him and he } \\
\text { remarried... he has a little boy and...he still sort of keeps in touch with my mother } \\
\text { and called for birthdays and mother's day which I'm fine with..That's } \\
\text { fine.. Whatever they want to have with him that's fine but I just didn't want } \\
\text { anything to do with him........ don't know...I feel like the family would have } \\
\text { been much closer. My brothers and sisters are still very supportive of me or with } \\
\text { me but they did keep a relationship with the father...but not as close as it used to } \\
\text { be. }\end{array}$ \\
\hline Christie & $\begin{array}{l}\text { I feel I was supported and I was also supported by my mom and um and she } \\
\text { would always send me to a baby sitter and not leave me in the house with my } \\
\text { father when he was intoxicated. So, and she left him... I felt like it was my fault } \\
\text { but at the same time I think that it helped me that she was just looking out for my } \\
\text { well being. My family was just looking out for me the whole time...I felt scared } \\
\text { at first, scared and ashamed at first like this can't be happening to me and then I } \\
\text { felt like this is my sister and my mom worked all the time and this is like my } \\
\text { mom figure and she helped me so I just came out told her... I felt relieved and in } \\
\text { between shamed, guilty, I felt like killing him, I felt all type of stuff. I felt dirty. }\end{array}$ \\
\hline Delores & $\begin{array}{l}\text { Relief...yeah. I actually I felt like she was my mom for a minute. She hugged } \\
\text { me....She hold me in her arms like a mom would have done. Like protection. } \\
\text { Yeah. Cause I would have knew that. I always thought that that is how life was } \\
\text { suppose to be }\end{array}$ \\
\hline Emily & $\begin{array}{l}\text { Well. I feel better, a little bit better. And I started to think less, a little less about } \\
\text { it. Sometimes I get that flash...not all the time. But then something happen and I } \\
\text { feel bad. I start thinking about that. Then I start thinking about when I little that I } \\
\text { can't concentrate in school. Sometime, I don't want to go to school. I escape } \\
\text { cause I don't want to go there. I feel like I want to die because of what happened. }\end{array}$ \\
\hline
\end{tabular}


Table 10. Survivor Responses to Research Question 7

\begin{tabular}{|c|c|c|}
\hline & $\begin{array}{c}\text { Response } \\
\text { Received to } \\
\text { Disclosure }\end{array}$ & $\begin{array}{l}\text { Did the survivors' self-perceived response following disclosure impact } \\
\text { future help seeking and subsequent disclosure? }\end{array}$ \\
\hline Bethany & $\begin{array}{l}\text { Positive } \\
\text { Response }\end{array}$ & $\begin{array}{l}\text {...It's not that they shut me out but we just don't talk about it. But I } \\
\text { have just gotten to a point where I just want to be by myself. I just } \\
\text { prefer to be by myself. I don't handle crisis that well either. I fall apart and } \\
\text { you'd have to pick me up in pieces. Actually } 2008 \text { is when I really had it up } \\
\text { to here with my life....My son or my sister came with my mom and they } \\
\text { brought me to the hospital and I checked into the Pond House and at the } \\
\text { same I was glad, at the same time I was nervous for what my kids were } \\
\text { going think about me. So I kind of faked that I was ok to leave so that they } \\
\text { would discharge me... There were times that I wish I could have gone back } \\
\text { since } 2008 \text { to } 2009 \text { but I need to hold it together for my kids.....This whole } \\
\text { building (SCSI) and like I've done IOP twice because I enjoy coming here } \\
\text { talking when I can and hearing. This is the only place that I go to besides } \\
\text { going to Walgreens. }\end{array}$ \\
\hline Christie & $\begin{array}{l}\text { Positive } \\
\text { Response }\end{array}$ & $\begin{array}{l}\text { I don't talk about it a lot unless I have time to. My meds...I need to get } \\
\text { back on my meds this Friday. I don't think about it really. I just watch out } \\
\text { for the ones I got now....I don't talk about it unless I'm with the psychiatrist } \\
\text { or something. But I don't just say "Oh, I was sexually molested."...I been in } \\
\text { IOP but I'm going to get one once I'm done with IOP....I need to get back } \\
\text { into church. I do pray. I do do those things. I need to find a church out here } \\
\text { because I was in Virginia for a while. }\end{array}$ \\
\hline Emily & $\begin{array}{l}\text { Positive } \\
\text { Response }\end{array}$ & $\begin{array}{l}\text { No. I don't tell nobody because I very afraid. I afraid so I don't say } \\
\text { nothing to nobody. Nobody. Cause I very afraid that something could } \\
\text { happen to my family or this guy could do something so I live my whole life } \\
\text { in fear that something could happen if I say something. I keep my feelings in } \\
\text { and everything.... No. I just don't want to tell nobody... only her...Cause I } \\
\text { feel very scared at the time. She say I need to talk about it more but I feel } \\
\text { like uncomfortable cause I feel real bad, nervous and everything so I don't } \\
\text { want to talk about it. }\end{array}$ \\
\hline Flora & $\begin{array}{l}\text { Negative \& } \\
\text { Positive } \\
\text { Responses }\end{array}$ & $\begin{array}{l}\text { I didn't tell anyone. I had no friends. People who knew me, who were my } \\
\text { friends were also friends with my family so I couldn't tell them. I didn't talk } \\
\text { about it with them because if I was to say something to them, they would } \\
\text { have brought it back and said something to my family that I'm still talking } \\
\text { about it so it stayed dead and buried....But I mostly kept everything to } \\
\text { myself so my husband didn't know anything either. The only person that } \\
\text { knew that it happened was somebody that I was with some time ago. }\end{array}$ \\
\hline
\end{tabular}


Table 11. Survivor Responses to Research Question 8

\begin{tabular}{|c|c|}
\hline & $\begin{array}{l}\text { What suggestions would a survivor of CSA give to clinicians, teachers, parents } \\
\text { regarding disclosure of CSA? }\end{array}$ \\
\hline Bethany & $\begin{array}{l}\text { It's painful, it's horrible, um..I think by knowing it and helping that person in the } \\
\text { early stage...things might be different as they get older. I think getting or letting } \\
\text { assuring the child, keep reminding the child that it is ok to speak out. As they } \\
\text { keep reminding people that cigarettes give cancer, wear your seatbelt everywhere } \\
\text { that should be told to kids at an early age because a child sees things differently. }\end{array}$ \\
\hline Christie & $\begin{array}{l}\text { Just tell someone. It don't matter who, just tell someone because when you keep } \\
\text { letting it go on, it haunt you even more. }\end{array}$ \\
\hline Delores & $\begin{array}{l}\text { Um...I been trying to stay clean and stuff and a case manager or someone who } \\
\text { cares can really help. I been trying to stay clean since I met her. She been there } \\
\text { with me through all the deaths. Every funeral, every wake, every time I had to go } \\
\text { to the hospital with one of my sisters, she was there with me. She was there every } \\
\text { step of the way. Alliance for Living has been a big help for me. All of them were } \\
\text { there when my mom died and they've been there to help me with my sexual } \\
\text { abuse trauma. Big time. I know if I didn't use, I wouldn't have to worry about } \\
\text { being sexually abused or being raped. I want to stop the prostitution and stuff but } \\
\text { when I relapse, I don't care about nothing. }\end{array}$ \\
\hline Emily & $\begin{array}{l}\text { Um.....hmmm.....Sometimes if you say something to somebody the same thing } \\
\text { that happen to you happen to them. Umm. I prefer to stay quiet. I only tell to my } \\
\text { counselor. But right now, I don't know if I tell Jennifer because I forget } \\
\text { everything. My mind is not good. I don't know I got this appointment today. I } \\
\text { forgot. Somebody call me and tell me that I got this appt. I forgot. I forgot. I got } \\
\text { bad memory. I don't know why. Maybe cause I don't want to think anything. I } \\
\text { forgot everything. }\end{array}$ \\
\hline Flora & $\begin{array}{l}\text { It might not change anything. But as soon as a child feels like they have been } \\
\text { molested or raped, go to somebody, if it's a teacher, a friends parent, go and talk } \\
\text { to them. Don't let anyone tell them not to do it....One, they'll be able to talk to } \\
\text { someone about it and get it out in the open and share what happened. When the } \\
\text { person understand...There is no faking. There's no faking being molested. Once } \\
\text { they start talking and explaining the situation, there is no way the person is not } \\
\text { going to believe that child aint been raped. There is no faking being raped. If you } \\
\text { can't talk to your parents, talk to a friend's mother. Talk to a teacher. If I had } \\
\text { somebody to talk to..... Talk to a teacher, a friend, you're better off getting } \\
\text { support from a stranger than your family. I tell my daughter's best friend that if } \\
\text { she ever needs me to talk to her about anything, my door is always open. }\end{array}$ \\
\hline
\end{tabular}


Table 12. Psychological Sequalae for each Survivor

\begin{tabular}{|c|c|c|}
\hline & Psychological Sequalae & $\begin{array}{l}\text { Response when asked "Did you use drugs and alcohol } \\
\text { to cope?" }\end{array}$ \\
\hline Angela & $\begin{array}{c}\text { Depression } \\
\text { Serious Suicide Attempt }\end{array}$ & $\begin{array}{l}\text { No not drinking or smoking when I was younger I tried } \\
\text { to kill myself...I tried to take pills because it was just too } \\
\text { painful I just wanted it to end }\end{array}$ \\
\hline Bethany & $\begin{array}{l}\text { Depression } \\
\text { Brief period of binge } \\
\text { drinking }\end{array}$ & $\begin{array}{l}\text { No I never did because I was afraid but when I did } \\
\text { divorce, I went on a } 4 \text { year drinking...sleeping around } \\
\text { binge with high rush. I was drinking everyday and } \\
\text { sleeping with men that I met at the bar that same day. }\end{array}$ \\
\hline Christie & $\begin{array}{c}\text { Depression } \\
\text { Substance Dependence }\end{array}$ & $\begin{array}{l}\text { All of that. Before I picked up drugs and alcohol...I used } \\
\text { that stuff to numb me out. }\end{array}$ \\
\hline Delores & $\begin{array}{l}\text { Depression } \\
\text { Substance Dependence } \\
\text { Prostitution/Sexually } \\
\text { Promiscuous }\end{array}$ & $\begin{array}{l}\text { I was into heroin from I was } 13 \text { so when I was } 18 \text { and I } \\
\text { started to do prostitution to support my habit. } \\
\text { I didn't want to deal with it. So I shot dope for a while so } \\
\text { I didn't have to deal with it... That's what I did...I did } \\
\text { anything to cope. I did any drug that was available, but } \\
\text { heroin was my drug of choice. }\end{array}$ \\
\hline Emily & $\begin{array}{l}\text { Depression } \\
\text { Hallucinations } \\
\text { Suicidal Ideation }\end{array}$ & $\begin{array}{l}\text { Drugs. Drugs. I used drugs. And a consequence about } \\
\text { that is..I hear voice too. Sometimes my voices tell me to } \\
\text { kill myself and something like that...I do a few times } \\
\text { with overdose. I take a overdose a few times. }\end{array}$ \\
\hline Flora & $\begin{array}{c}\text { Bipolar Disorder } \\
\text { Anxiety } \\
\text { Serious Suicide Attempts }\end{array}$ & $\begin{array}{l}\text { Nope..I didn't. I got very depressed. My ways was the } \\
\text { easy way out. Attempted suicide cause I got tired of it. I } \\
\text { just wanted to forget about it. I'd get more depressed and } \\
\text { that's when Florida... When I was in Florida in my mid } \\
\text { 30s, I was diagnosed with Bipolar and manic depression } \\
\text { and anxiety and I took meds for it. But during the abuse } \\
\text { with him, he always bought me something. He had a } \\
\text { house you know. I had something that I never thought } \\
\text { that I would have at an early age. I had a beautiful house. } \\
\text { I had credit cards. I had more credit cards than I knew } \\
\text { what to do with. So the abuse, the abuse, the physical } \\
\text { abuse, the verbal abuse I tuned it out and didn't care } \\
\text { because I thought that's how I was supposed to be } \\
\text { treated. } \\
\text { I just tried to commit suicide. }\end{array}$ \\
\hline
\end{tabular}


Table 13. Percentage of Responses to SCID Items

Structured Clinical Interview for Axis I Disorders (SCID) Items

Absent or False Subthreshold

Threshold or

True

\section{FEAR, HELPLESSNESS, HORROR}

How did you react when the sexual abuse

$100 \%$

happened? (Were you very afraid or did you feel

terrified or helpless?)

\section{PERSISTENT RE-EXPERIENCING}

Do you think about the sexual abuse when you

$17 \% \quad 83 \%$

don't want to or do thoughts about the abuse

come to you suddenly when you don't want them

to?

...... What about having dreams about the abuse

$17 \%$

......What about finding yourself acting or

$17 \% \quad 83 \%$

feeling as if you were back in the situation?

What about getting very upset when

something reminds you of the abuse

......What about having physical symptoms-like

$17 \%$

$17 \%$

$67 \%$

breaking out in a sweat, breathing heavily, or irregularly, or your heart pounding or racing when something reminds you of the abuse?

\section{AVOIDANCE OF STIMULI ASSOCIATED WITH THE TRAUMA}

...... Have you made a special effort to avoid $50 \% \quad 50 \%$ thinking or talking about what happened?

Have you ever stayed away from things or people that remind you of the abuse?

...... Have you been unable to remember some

$17 \%$

$17 \%$

$67 \%$

important part of what happened?

...... Have you been much less interested in doing things that used to be important to you, like seeing friends, watching TV? 


\begin{tabular}{|c|c|c|c|c|}
\hline $\begin{array}{l}\text { Structured Clinical Interview for Axis I Disorders } \\
\text { (SCID)Items }\end{array}$ & Absent or False & Subthreshold & $\begin{array}{c}\text { Threshold or } \\
\text { True }\end{array}$ & $\begin{array}{c}\text { True } \\
\text { past } 6 \\
\text { months }\end{array}$ \\
\hline
\end{tabular}

Have you felt distant or cut off from others?

.Have you felt "numb" or like you no longer

have strong feelings about anything or loving

feelings for anyone?

...... Did you notice a change in the way you

think about or plan for the future?
$17 \%$

$33 \%$
$83 \%$

$67 \%$

$100 \%$

\section{PERSISTENT SYMPTOMS OF \\ INCREASED AROUSAL NOT PRESENT \\ BEFORE THE TRAUMA}

Have you had trouble sleeping?

$100 \%$

......Have you been unusually irritable-What about outbursts of anger?

$33 \%$

$67 \%$

......Have you had trouble concentrating?

$33 \%$

$67 \%$

......Have you been watchful or on guard even

$17 \%$

$67 \%$

$17 \%$

when there was no reason to be?

have you been jumpy or easily startled, like

$83 \%$

$17 \%$

by sudden noises? 
Appendix II

Diagnostic and Statistical Manual-IV (DSM-IV) Criteria for Posttraumatic Stress

Disorder (PTSD) 


\section{Posttraumatic Stress Disorder Diagnostic Criteria}

(American Psychiatric Association, 2000)

A. The persona has been exposed to a traumatic event in which both of the following were present:

(1) The person experienced, witnessed, or was confronted with an event or events that involved actual or threatened death or serious injury, or a threat to the physical integrity of self or others

(2) The person's response involved intense fear, helplessness or horror. Note: In children, this may be expressed instead by disorganized or agitated behavior

B. The traumatic event is persistently re experienced in one (or more) of the following ways:

(1) recurrent and intrusive distressing recollections of the event, including images, thoughts, or perceptions. Note: In young children, repetitive play may occur in which themes or aspects of the trauma are expressed.

(2) recurrent distressing dreams of the event. Note: In children, there may be frightening dreams without recognizable content.

(3) acting or feeling as if the traumatic event were recurring (includes a sense of reliving the experience, illusions, hallucinations, and dissociative flashback episodes, including those that occur on awakening or when intoxicated). Note: In young children, trauma-specific reenactment may occur.

(4) intense psychological distress at exposure to internal or external cues that symbolize or resemble an aspect of the traumatic event

(5) physiological reactivity on exposure to internal or external cues that symbolize or resemble an aspect of the traumatic event

C. Persistent avoidance of stimuli associated with the trauma and numbing of general responsiveness (not present before the trauma), as indicated by three (or more) of the following

(1) efforts to avoid thoughts, feelings, or conversations associated with the trauma

(2) efforts to avoid activities, places, or places that arouse recollections of the trauma 
(3) inability to recall an important aspect of the trauma

(4) markedly diminished interest or participation in significant activities

(5) feeling of detachment or estrangement from others

(6) restricted range of affect (e.g. unable to have loving feelings)

(7) sense of a foreshortened future (e.g. does not expect to have a career, marriage, children, or a normal life span)

D. Persistent symptoms of increased arousal (not present before the trauma), as indicated by two (or more) of the following

(1) difficulty falling or staying asleep

(2) irritability or outburst of anger

(3) difficulty concentrating

(4) hypervigilance

(5) exaggerated startle response

E. Duration of the disturbance (symptoms in Criteria B,C, and D is more than 1 month.

F. The disturbance causes clinically significant distress or impairment in social, occupation, or other important areas of functioning.

Specify if:

Acute: if duration of symptoms is less than 3 months

Chronic: if duration of symptoms is 3 months or more

Specify if:

With Delayed Onset: If onset of symptoms is at least 6 months after the stressor 
Appendix III

Structured Clinical Interview for Axis I Disorders (Posttraumatic Stress Disorder Questionnaire)

$\&$

Interview Guide 


\section{Structured Clinical Interview for Axis I Disorders \\ (Posttraumatic Stress Disorder Questionnaire)}

I'd like to ask a few questions about specific ways that being sexually abused may have affected you.

(1) Fear, Helplessness, Horror

How did you react when the sexual abuse happened? (Were you very afraid or did you feel terrified or helpless?)

$1 \quad 2 \quad 3 \quad 4$

\section{(2) Persistent Re-experiencing (in one or more of the following ways)}

Do you think about the sexual abuse when you don't want to or do thoughts about the abuse come to you suddenly when you don't want them to?

$\begin{array}{llll}1 & 2 & 3 & 4\end{array}$

If NO: Did that ever happen?

What about having dreams about the abuse

$\begin{array}{llll}1 & 2 & 3 & 4\end{array}$

If No: Did that ever happen?

What about finding yourself acting or feeling as if you were back in the situation?

$\begin{array}{llll}1 & 2 & 3 & 4\end{array}$

If NO: Did that ever happen?

What about getting very upset when something reminds you of the abuse

$\begin{array}{llll}1 & 2 & 3 & 4\end{array}$

If NO: Did that ever happen?

......What about having physical symptoms - like breaking out in a sweat, breathing heavily, or irregularly, or your heart pounding or racing when something reminds you of the abuse?

$\begin{array}{llll}1 & 2 & 3 & 4\end{array}$

If NO: Did that ever happen?

ATLEAST ONE (2) SX IS CODED "3" OR “4" 
$?=$ Inadequate information $\quad 1=$ absent or false 2 = subthreshold $3=$ threshold or true $4=$ true past 6 months

\section{(3) Avoidance of Stimuli Associated with the Trauma (in 3 or more of the following ways)}

Since the sexual abuse....

......Have you made a special effort to avoid thinking or talking about what happened?

If NO: Did that ever happen?

$\begin{array}{llll}2 & 3 & 4\end{array}$

......Have you ever stayed away from things or people that remind you of the abuse?

If NO: Did that ever happen?

$\begin{array}{llll}1 & 2 & 3 & 4\end{array}$

...... Have you been unable to remember some important part of what happened?

If NO: Did that ever happen?

$\begin{array}{llll}1 & 2 & 3 & 4\end{array}$

...... Have you been much less interested in doing things that used to be important to you, like seeing friends, watching TV?

If NO: Did that ever happen?

$\begin{array}{llll}1 & 2 & 3 & 4\end{array}$

.....Have you felt distant or cut off from others?

If NO: Did that ever happen?

$\begin{array}{llll}1 & 2 & 3 & 4\end{array}$

......Have you felt "numb" or like you no longer have strong feelings about anything or loving feelings for anyone?

If NO: Did that ever happen?

$\begin{array}{llll}1 & 2 & 3 & 4\end{array}$

......Did you notice a change in the way you think about or plan for the future?

If NO: Did that ever happen? 


\section{ATLEAST THREE (3) SX IS CODED “3” OR}

"4"

$?=$ Inadequate information $1=$ absent or false 2 = subthreshold $3=$ threshold or true $4=$ true past 6 months 
(4) Persistent symptoms of increased arousal not present before the trauma ( 2 or more of the following symptoms)

Since the sexual abuse....

......Have you had trouble sleeping?

(What kind of trouble?)

If NO: Did that ever happen?

$\begin{array}{llll}1 & 2 & 3 & 4\end{array}$

......Have you been unusually irritable-What about outbursts of anger?

If NO: Did that ever happen?

$\begin{array}{llll}1 & 2 & 3 & 4\end{array}$

......Have you had trouble concentrating?

If NO: Did that ever happen?

$\begin{array}{llll}1 & 2 & 3 & 4\end{array}$

......Have you been watchful or on guard even when there was no reason to be?

If NO: Did that ever happen?

$\begin{array}{llll}1 & 2 & 3 & 4\end{array}$

......have you been jumpy or easily startled, like by sudden noises?

$\begin{array}{llll}2 & 3 & 4\end{array}$

If NO: Did that ever happen?

ATLEAST TWO (4) SX IS CODED "3" OR “4"

$?=$ Inadequate information $1=$ absent or false $2=$ subthreshold $3=$ threshold or true $4=$ true past 6 months 


\section{Interview Guide}

An Exploration of Response to Disclosure of Childhood Sexual Abuse and Help Seeking in a Clinical Sample of Adult Female Sexual Abuse Survivors

$\checkmark \quad$ I would like to talk a little more about your sexual abuse experience. I will not ask you to discuss specific details about your experience, but I would like you to describe your experience of disclosing that you were being sexually abused

Describe the process leading up to your disclosure

- How and when did you decide that you were going to tell someone?

- What barriers in disclosing did you perceive? Did you experience any barriers to disclosing $\gg>>$ wait and see if there is a spontaneous response before using probes

- Were you ever afraid to tell because of family values and ideals

- Were you ever afraid to tell because of how people in your community might react if they found out?

- Who did you disclose to?

- Why did you select this person to tell about your experience? Was there any specific reason that you selected this person to tell about your experience?

- What did you hope would happen as a result of telling this person? Now, let's talk a little more about what happened when you finally told that you were being sexually abused

Describe the response you received once you told about the abuse. Can you recall how the person responded to you? 
- How did the person respond?-Do you recall what he/she said?

- Do you think the person responded negatively or positively? How did you experience his/her response? Then you can probe more...were you surprised at this person's response?

- Overall, do you think your disclosure was supported or not supported?

- How did you feel after you told about your abuse? Can you recall how you felt....how this response affected you

$\checkmark$ Now let's talk some more about your experiences after disclosure-Could you describe what that was like? I'd like to talk some more about.....is that OK with you ( this is an example of process consent)

Describe how you reacted to the response that you received after telling about your abuse.-What did you do? Wait before probing

- After the initial disclosure, did you try to tell anyone else such as a friend, boyfriend, clergyman, therapist?-If so, was this helpful?

- Looking back, do you think that the response you received after telling about your abuse experience had an effect on whether or not you decided to tell anyone else or look for help elsewhere? Did you engage in any behaviors such as drinking, smoking, avoidance, angry outbursts?

Again looking back over your life, do you think your initial sexual abuse had any affect on your life? 
$\checkmark$ Do you think the response of the first person you disclosed to influenced your life in any way?

$\checkmark$ As an adult, I'd like to find out if you think your abuse experience affects you currently. Again plenty of pausing and waiting before probing

Describe what strategies have helped you deal with the experience of being sexually abused. Was there anything you did to help deal with ....

$\checkmark$ If anything, what would you have changed about the way you disclosed? Is there wish you had done differently?

$\checkmark$ If you had the opportunity to speak to clinicians, teachers, parents regarding disclosure of CSA what would you want them to know? 
Appendix IV

Demographic Questionnaire 
Date:

This brief questionnaire contains questions about your current living situation, level of education, employment status, etc. Please try to answer all questions that apply to you. If you do not know the answer to the question, if a question does not apply to you, or if you are uncomfortable answering a question, you may leave it blank.

1. How old are you?

2. What is your race?

1. European/European American

2. American Indian/Native American

3. Asian/Asian American//Pacific Islander

4. African /African American

5. Latina/o

6. Arab/Arab American

7. Bi-or Multi-racial/ethnic

8. Other:

3. Currently, do you live

1. Independently w/ support

2. Independently without support

3. With your parent(s) or other relative

4. With a partner

5. With a friend or roommate

6. Other:

4. What is your highest level of education

1. Some high school

2. Completed high school or a GED program

3. Some college

4. Bachelor's degree

5. Some graduate-level courses

6. Master's Degree

7. Doctorate Degree

5. Are you currently employed?

1. Yes, I am employed full time (20+ hours/week)

2. Yes, I am employed part time (less than 20 hours/week)

3. No, I am not employed and I do not receive any benefits

4. No, I am not employed and I collect unemployment

5. No, I am not employed and I receive SSD or SSI

6. No, I am not employed and I receive state assistance 
7. What is your current income?

1. $\$ 0$ to 10,000

2. $\$ 10,000$ to $\$ 19,000$

3. $\$ 20,000$ to $\$ 34,000$

4. $\$ 35,000$ to $\$ 50,000$

5. $\$ 50,000$ and above

8. In the past, did you receive any type of psychological treatment?

1. Yes

2. No

If yes, answer a

8a. What type(s) of treatment did you receive? (Please check all that apply) Individual therapy Group therapy Support groups Family therapy Medication Inpatient hospitalization Outpatient treatment Substance abuse treatment 
Appendix V

Informed Consent 


\section{INFORMED CONSENT FORM FOR RESEARCH}

\section{Dear Survivor:}

You are invited to take part in a research study looking at responses to disclosure of childhood sexual abuse. The form below describes this project in detail. Please feel free to ask the researcher any questions you may have. If you have more questions later, you may either contact Patricia Morokoff (401-874-4239) or Ginette Ferszt (401-874-5354). You must be at least 18 years old to participate in this research project.

\section{Description of the Project}

You are being asked to participate in a study examining how survivors of childhood sexual abuse describe the experience of disclosing that they were being sexually abused as well as how the person they told responded to the disclosure. Based on the response they received after disclosing, this study will ask survivors to describe the ways in which they reacted and whether or not respond to disclosure impacted future help seeking and subsequent disclosure.

Your name was provided for this study by Matt Waldo. You have provided oral consent to Matt Waldo or your clinician/case manager about being contacted for this study. Please be assured that all information that you provide during this study will be kept confidential and will NOT be shared with any staff members at Sound Community Services, Inc. The information that you share will be kept confidential by the researchers of this study.

Additionally, staff members at Sound Community Services, Inc. will not be made aware of whether or not you decided to participate in the study. Since interviews will be conducted at 165 State Street, New London, CT, the researcher(s) involved in this study will try to maintain confidentiality about whether or not you have decided to participate in this study.

Your decision to participate in this study will NOT affect your clinical care or the quality of services that you receive from your providers. The information that you provide will NOT become a part of your clinical record.

\section{What Will Be Done?}

This study will take at Sound Community Services, Inc. in a private office. If you decide to participate in the study, you will be asked some basic demographic questions, as well as provide information about your sexual abuse disclosure experience, the response you received, and how you coped with that response. You will be asked about how and when you decided that you were going to tell someone that you were being sexually abused. You will also be asked questions about who you decided to tell and why you chose that person to disclose your secret. Other questions that are included in the interview relate to how the person responded to your disclosure, whether the response was support or unsupportive, and how you reacted to the response you received.

Most of the questions will involve a conversation between you and the interviewer. This conversation will be tape recorded. Other questions will involve your responses using a paper and pencil. Following the interview, the audiotape will be transcribed and all 
identifying information, including names and locations you may mention, will be removed. The audiotape of the interview will be stored in a locked file cabinet for three years, and then destroyed.

The interview portion of this study should take between 1 hour and $1 \frac{1}{2}$ hours. The paper and pencil portion of this study will take approximately 5 minutes to complete.

\section{Risks or Discomfort}

Participation in this study could cause discomfort, as you will be asked to reflect back on a time in your life when you felt violated. For counseling [need to discuss counseling options]

\section{Benefits of this Study}

You will be compensated with a $\$ 25$ gift card for your time and participation in this study.

\section{Confidentiality}

Participation in this project is confidential and information that you share will not be linked to your identity in any publications or presentations arising from this study. Tape transcriptions and any written notes taken during the interview will contain first names only. Your name or any identifying information will not be used when reporting the results of this study. In order to ensure privacy and confidentiality of information shared during this study, all materials collected will be stored in a locked file cabinet at the University of Rhode Island in the Department of Psychology for the duration of 3 years. All materials pertaining to this study will be destroyed after 3 years.

\section{Decision to Quit at Any Time}

Your decision to participate in this study is completely voluntary. You do not have to participate in this study, and you may quit at any time. You may also refuse to answer any questions you choose. There are no financial costs to you for participation in this research project. 


\section{Rights and Complaints}

If you have any questions or concerns about this study, you may contact Trudy-Ann Gayle at (401) 874-2193 or Tgayleuri@yahoo.com. You may also contact Dr. Patricia Morokoff at (401) 874-4239 or Dr. Ginette Ferszt also at (401) 874- 5345 anonymously, if you choose. In addition, if you have other concerns about this study or if you have questions about your rights as a research survivor, you may contact the University of Rhode Island's Vice President for Research, 70 Lower College Road, Suite 2, URI, Kingston, RI, (401) 874-4328.

I have read the consent form and have no further questions about my participation in this project at this time. I understand that I may ask any additional questions at any time, that my participation in this project is voluntary, and that I may withdraw from this project at any time. My signature on this form means that I understand the information provided and I agree to participate in this project.

Signature of Survivor

Name (Please print)
Signature of Researcher

Date

Date

THIS FORM IS IDENTICAL TO THE ATTACHED FORM. PLEASE SIGN AND DATE THE ATTACHED FORM AND KEEP IT FOR YOUR RECORDS. 


\section{CONSENT TO AUDIOTAPE INTERVIEW}

This interview will be audiotaped by the researcher as a way to achieve accuracy in telling your story. The audiotape will be transcribed and all identifying information, including names and locations you may mention will be removed.

Neither the audiotape nor the transcript will be connected with your name. The audiotape will be stored in a locked file cabinet for three years, and then destroyed.

If you wish to stop taping at any point, temporarily or for the remainder of the interview, you only need to ask the researcher to turn the recorder off.

Your name or any identifying information will not be used when reporting the results of this study. In order to ensure privacy and confidentiality of information shared during this study, all audio-taped materials collected will be stored in a locked file cabinet at the University of Rhode Island in the Department of Psychology for the duration of 3 years. All materials pertaining to this study will be destroyed after 3 years.

You have read the Audiotape Consent Form. Your questions have been answered. Your signature on this form means that you understand the information and you agree to be audio-taped in this study.

Signature of Survivor

Name (Please print)
Signature of Researcher

Name (please print)

Date

Date

THIS FORM IS IDENTICAL TO THE ATTACHED FORM. PLEASE SIGN AND DATE THE ATTACHED FORM AND KEEP IT FOR YOUR RECORDS. 


\section{Bibliography}

Alaggia, R. (2004). Many ways of telling: expanding conceptualizations of child sexual abuse disclosures. Child Abuse \& Neglect, 28, 1213-1227.

Alaggia, R. (2001). Cultural and religious influences in maternal response to intrafamilial child sexual abuse: charting new territory for research and treatment. Journal of Child Sexual Abuse, 10(2), 41-60.

Alaggia, R., \& Turton, J. V. (2005). Against the odds: The impact of woman abuse on maternal response to disclosure of child sexual abuse. Journal of Child Sexual Abuse, 14(4), 95-113.

American Psychiatric Association. (2000). Diagnostic criteria from DSM-IV-TR.

Anderson, D.G., and Hatton, D.C. (2000) Accessing vulnerable populations for research. Western Journal of Nursing Research, 22, 244-251.

Berliner, L.,\& Conte, J. R. (1995). The effects of disclosure and intervention of sexually abused children. Child Abuse \& Neglect, 19(3), 371-384.

Brewin, C. \&Valentine, A. (2000). Meta- analysis of risk factors for posttraumatic stress disorder in trauma-exposed adults. Journal of Consulting Clinical Psychology, $68(5), 748-766$.

Briere, J., Elliott, D. (2003). Prevalence and psychological sequelae of self-reported childhood physical and sexual abuse in a general population sample of men and women. Child Abuse \& Neglect. Vol 27(10), 1205-1222.

Burnard, P. (2005). Books, book reviews and writing. Journal of Psychiatric and Mental Health Nursing, 12(3), 257-258. 
Boney-McCoy, S. Finkelhor, D. (1998). Psychopathology associated with sexual abuse: A reply to Nash, Neimeyer, Hulsey, and Lambert (1998). Journal of Consulting and Clinical Psychology. Vol 66(3), 572-573.

Classen, C., Palesh, O., Aggarwal, R. (2005). Sexual revictimization: a review of the empirical literature. Trauma, Violence, \& Abuse. Vol 6(2), 103-129.

Cowles, K. V. (1988). Issues in qualitative research on sensitive topics. Western Journal of Nursing Research, 10(2),163-179.

Davies, D., Dodd, J. (2002). Qualitative research and the question of rigor. Qualitative Health Research. Special Issue: Emotional Responses. Vol 12(2), 279-289.

Dearnley, K., Bloomfield, L., Kendall, S., Applin, L., Attarzadeh, V., Edwards, L., Hinshelwood, L., Lloyd, P., Newcombe, T. (2005). A qualitative study exploring the experiences and views of mothers, health visitors and family support centre workers on the challenges and difficulties of parenting. Health and Social Care in the Community, 13(1), 46-55.

Elliot, D., \& Briere, J. (1994). Forensic sexual abuse evaluations of older children: Disclosures and symptomology. Behavioral Sciences and Law, 12, 261-277.

Enns, C., Campbell, J., Courtois, C., Gottlieb, M., Lese, K., Gilbert, M., Forrest, L. (1998). Working with adult clients who may have experienced childhood abuse: Recommendations for assessment and practice. Professional Psychology: Research and Practice. Vol 29(3), 245-256.

Everill, J., \&Waller, G. (1994). Disclosure of sexual abuse and psychological adjustment in female undergraduates. Child Abuse \& Neglect, 19, 93-100. 
First, M., Spitzer, R.L., Gibbon, M., \& Williams, J.B. (1997). Structured Clinical Interview for DSM-IV Axis I Disorders. Washington, DC: American Psychiatric Press.

Graneheim, H., \& Lundman, B. (2004). Qualitative content analysis in nursing research: concepts, procedures and measures to achieve trustworthiness. Nurse Education Today, 24(2), 105-112.

Gries, L. T., Goh, D. S., Andrews, M. B., Gilbert, J., Praver, F., \& Stelzer, D. N. (2000). Positive reaction to disclosure and recovery from child sexual abuse. Journal of Child Sexual Abuse, 9, 29-51.

Guba, E. Lincoln, Y. Fourth generation evaluation. Thousand Oaks, CA, US: Sage Publications, Inc. (1989) pp. 294.

Heflin, A. H., Deblinger, E., \& Fisher, C. D. (2000). Child sexual abuse. In A. Freeman \& F. M. Dattilio (Eds.), Cognitive behavioral strategies in crisis intervention (2nd ed., pp. 166-195). New York: Guilford Press.

Henwood, K.L., Finn, M. and Shirani, F. (2008). Use of visual methods to explore parental identities in historical time and social change: Reflections from the 'menas-fathers' project. Qualitative Researcher, 9, 112-115.

Hershkowitz, I., Lanes, O., \& Lamb, M. (2007). Exploring the disclosure of child sexual abuse with alleged victims and their parents. Child Abuse and Neglect, 31, 111123.

Hughes, J. N. (2000). The essential role of theory in the science of teaching children: Beyond empirically supported treatments. Journal of School Psychology, 38, 301330. 
Koch, J. (2006). Establishing rigour in qualitative research: the decision trail. Journal of Advanced Nursing, 53(1), 91-100.

Krippendorff, K. \& Bock, M. (2008): The content analysis reader. Thousand Oaks, CA: Sage Publications.

Krippendorff, K.(2004). Content analysis: an introduction to its methodology. 2nd edition, Thousand Oaks, CA: Sage Publications.

Leonard, B. J., Hellerstedt, W. L., \& Josten, L. (1997). Association of maternal psychological functioning to pathology in child sexual abuse victims. Issues in Mental Health Nursing, 18, 587-601.

Loeb, T., Williams, J. Carmona, J., Rivkin, J., Wyatt, G., Chin, A. (2002). Child sexual abuse: associations with the functioning of adolescent and adults. Annual Review of Sex Research, 13, 307-345.

Matsakis, A. (1991). When the Bough Breaks. Oakland, CA: New Harbinger Publications.

Polit, D. \& Beck, C. (2008) Nursing research: generating and assessing evidence for nursing practice Eighth Edition. Lippincott Williams \&Wilkins. Philadelphia, PA.

Nagel, D., Putnam, F., \& Noll, J. (1997). Disclosure patterns of sexual abuse and psychological functioning at a 1-year follow- up. Child Abuse and Neglect , 21 (2), 137-147.

Paine, M., \& Hansen, D. (2002). Factors influencing children to self-disclose sexual abuse. Clinical psychology review , 22, 271-295.

Rose, K. \& Webb, C. (1998). Analyzing data: maintaining rigor in a qualitative study. Qualitative Health Research, 8(4), 556-562. 
Roth, D. (1997). Childhood sexual abuse: using Connexions Focusing Technique (CFT) model and Adlerian Theory with women survivors of childhood sexual abuse. Dissertation Abstracts International: Section B: The Sciences and Engineering $57(8-b), 5342$.

Runtz, M., Schallow, J. (1997). Social support and coping strategies as mediators of adult adjustment following childhood maltreatment. Child Abuse \& Neglect. Vol 21(2), 211-226.

Sinclair, B. B. (1999). Predicting the impact of child sexual abuse: A model of attachment, coping, and disclosure. Dissertation Abstracts International: Section B: The Sciences and Engineering, 60 (3-B), 1316.

Staller, K., \& Nelson-Gardell, D. (2005). "A Burden in your Heart": lessons of disclosure from female preadolescent and adolescent survivors of sexual abuse. Child Abuse and Neglect, 29, 1415-1432.

Somer, E., \& Szwarcberg, S. (2001). Variable in delayed disclosure of childhood sexual abuse. American Journal of Orthopsychiatry, 71 (3), 332-341.

Sorensen, T., \& Snow, B. (1991). How children tell: the process of disclosure of child sexual abuse. Child Welfare, 70, 3-15.

Wyatt, G., Myers, H., Williams, J. Kitchen, C., Loeb, T., Carmona, J., et al. (2002). Does a history of trauma contribute to HIV risk for women of color? Implications for prevention and policy. American Journal of Public Health, 92(4), 660-665. 